\title{
Comparing the Antiseizure and Neuroprotective Efficacy of LY293558, Diazepam, Caramiphen, and LY293558-Caramiphen Combination against Soman in a Rat Model Relevant to the Pediatric Population
}

\author{
James P. Apland, Vassiliki Aroniadou-Anderjaska, Taiza H. Figueiredo, \\ Volodymyr I. Pidoplichko, Katia Rossetti, and Maria F. M. Braga \\ Neuroscience Branch, U.S. Army Medical Research Institute of Chemical Defense, Aberdeen Proving Ground, Maryland (J.P.A.); \\ and Departments of Anatomy, Physiology, and Genetics (V.A.-A., T.H.F., V.I.P., K.R., M.F.M.B.) and Psychiatry (V.A.-A., M.F.M.B.), \\ F. Edward Hébert School of Medicine, Uniformed Services University of the Health Sciences, Bethesda, Maryland
}

Received October 26, 2017; accepted February 8, 2018

\begin{abstract}
The currently Food and Drug Administration-approved anticonvulsant for the treatment of status epilepticus (SE) induced by nerve agents is the benzodiazepine diazepam; however, diazepam does not appear to offer neuroprotective benefits. This is of particular concern with respect to the protection of children because, in the developing brain, synaptic transmission mediated via $\mathrm{GABA}_{\mathrm{A}}$ receptors, the target of diazepam, is weak. In the present study, we exposed 21-day-old male rats to $1.2 \times \mathrm{LD}_{50}$ soman and compared the antiseizure, antilethality, and neuroprotective efficacy of diazepam $(10 \mathrm{mg} / \mathrm{kg})$, LY293558 (an AMPA/GluK1 receptor antagonist; $15 \mathrm{mg} / \mathrm{kg}$ ), caramiphen (CRM, an antimuscarinic with NMDA receptorantagonistic properties; $50 \mathrm{mg} / \mathrm{kg}$ ), and LY293558 (15 mg/kg) + CRM $(50 \mathrm{mg} / \mathrm{kg}$ ), administered 1 hour after exposure. Diazepam, LY293558, and LY293558 + CRM, but not CRM alone, terminated SE; LY293558 + CRM treatment acted
\end{abstract}

significantly faster and produced a survival rate greater than $85 \%$. Thirty days after soman exposure, neurodegeneration in limbic regions was most severe in the CRM-treated group, minimal to severe-depending on the region-in the diazepam group, absent to moderate in the LY293558-treated group, and totally absent in the LY293558 + CRM group. Amygdala and hippocampal atrophy, a severe reduction in spontaneous inhibitory activity in the basolateral amygdala, and increased anxiety-like behavior in the open-field and acoustic startle response tests were present in the diazepam and CRM groups, whereas the LY293558 and LY293558 + CRM groups did not differ from controls. The combined administration of LY293558 and CRM, by blocking mainly AMPA, GluK1, and NMDA receptors, is a very effective anticonvulsant and neuroprotective therapy against soman in young rats.

\section{Introduction}

Acute exposure to nerve agents can cause brain damage or death. The primary action of these organophosphorus neurotoxins is inhibition of acetylcholinesterase (Sirin et al., 2012). Death may ensue because of the peripheral cholinergic crisis that follows acetylcholinesterase inhibition and/or the prolonged seizures and status epilepticus (SE), which are initiated by excessive accumulation of acetylcholine in neuronal synapses in the brain and overstimulation of cholinergic receptors. If death is prevented by pharmacologic

The views of the authors do not purport to reflect the position or policies of the Department of Defense or the U.S. Army.

Supported by the CounterACT Program, National Institutes of Health Office of the Director (NIH OD), and the National Institute of Neurologic Disorders and Stroke (NINDS) [Grant 5U01NS058162-07]

https://doi.org/10.1124/jpet.117.245969. intervention, brain damage may still occur, caused primarily by the SE (Shih et al., 2003; Prager et al., 2013) but also via mechanisms independent of seizures (Yokoyama, 2007; Pereira et al., 2014). The neurologic, cognitive, and/or emotional deficits that follow nerve agent-induced brain damage are long-lasting, as we know from animal studies (AroniadouAnderjaska et al., 2016), but also from studies in humans after the terrorist attacks in Matsumoto in 1994 and Tokyo in 1995 (Murata et al., 1997; Sekijima et al., 1997; Ohtani et al., 2004; Yanagisawa et al., 2006). Unfortunately, devastating nerve agent attacks occur nowadays as well, as in Syria (Dolgin, 2013), and the long-term health consequences on the surviving victims, many of which are children, may become known only after these conflicts end.

Seizures, after acute nerve agent exposure, are triggered by muscarinic receptor hyperstimulation owing to elevated acetylcholine, and muscarinic receptor antagonists are effective

ABBREVIATIONS: AMPA, ( $\alpha$-amino-3-hydroxy-5-methyl-4-isoxazolepropionic acid); BLA, basolateral amygdala; CE, coefficient of error; CRM, caramiphen; FJC, Fluoro-Jade C; GluK1Rs, kainate receptors containing the GluK1 subunit; HI-6, (1-(2-hydroxyiminomethylpyridinium)-3-(4carbamoylpyridinium)-2-oxapropane dichloride; IQR, interquartile range; sIPSC, summated spontaneous induced pleuripotent stem cell; LY293558, $(3 S, 4 a R, 6 R, 8 a R)-6-[2-(1(2) H$-tetrazole-5-yl)ethyl]decahydroisoquinoline-3-carboxylic acid; PBS, phosphate-buffered saline; SE, status epilepticus. 
in halting nerve agent-induced seizures if they are administered shortly after exposure (Lallement et al., 1998; Shih and McDonough, 1999; Skovira et al., 2010). Muscarinic receptor hyperstimulation is followed by glutamatergic hyperactivity, which intensifies and sustains SE (McDonough and Shih, 1997) and is largely responsible for excitotoxic neuronal damage (Shih et al., 2003; Deshpande et al., 2014a). Excessive glutamatergic activity can be counteracted by blocking certain types of glutamate receptors or by enhancing $\mathrm{GABA}_{\mathrm{A}}$ receptor-mediated inhibition. Accordingly, benzodiazepines, which are positive allosteric modulators of $\mathrm{GABA}_{\mathrm{A}}$ receptors, are the first-line treatment of SE, regardless of its cause (Cherian and Thomas, 2009; Trinka and Kälviäinen, 2017), and diazepam (a benzodiazepine) is the currently Food and Drug Administration-approved anticonvulsant for treating nerve agent-induced seizures. Benzodiazepines, however, lose their efficacy as the latency of administration from the onset of SE increases (Walton and Treiman, 1991; Jones et al., 2002; Goodkin et al., 2003; Cherian and Thomas, 2009; McDonough et al., 2010; Todorovic et al., 2012; Niquet et al., 2016; Trinka and Kälviäinen, 2017); anticonvulsant efficacy at delayed post-SE-onset time points is necessary in a scenario of mass exposure to nerve agents when medical assistance may not be available immediately. Furthermore, the neuroprotective efficacy of benzodiazepines is limited (de Araujo Furtado et al., 2010; Langston et al., 2012; Apland et al., 2014). The drawbacks of the benzodiazepines in terminating seizures and protecting from brain damage may relate to the internalization and downregulation of $\mathrm{GABA}_{\mathrm{A}}$ receptors that occur as SE progresses (Goodkin et al., 2005; Naylor et al., 2005; Deeb et al., 2012). In contrast, glutamate receptors are upregulated during prolonged seizure activity (Naylor et al., 2013; Rajasekaran et al., 2013; Wasterlain et al., 2013). Therefore, antagonizing directly the hyperactivity of the glutamatergic system rather than attempting to enhance GABAergic activity may be a more efficacious approach for terminating nerve agent-induced seizures and protecting from brain damage.

We have previously demonstrated that LY293558 ( $(3 S, 4 a R, 6 R, 8 a R)-6$-[2-(1(2)H-tetrazole-5-yl)ethyl]decahydroisoquinoline-3-carboxylic acid; Bleakman et al., 1996), an antagonist of both AMPA receptors and the kainate receptors that contain the GluK1 subunit (formerly known as GluR5 subunit; see Jane et al., 2009), stops seizures induced by soman and significantly protects against neuronal damage, even if it is administered at 1 hour or longer after the exposure in either adult (Figueiredo et al., 2011b) or immature (P21) rats (Miller et al., 2015). In adult rats, LY293558 is far superior to DZP in protecting against soman-induced brain damage (Figueiredo et al., 2011b; Apland et al., 2013, 2014; Aroniadou-Anderjaska et al., 2016). Comparisons of the efficacies of these two anticonvulsants in protecting the developing brain have not been made so far; the first aim of the present study was to provide these data. The second aim was to determine whether combining LY293558 with an antagonist of NMDA receptors can offer greater neuroprotection against soman-induced damage than that of LY293558 alone. Therefore, we tested the combination of LY293558 with caramiphen (CRM), an M1 muscarinic receptor antagonist (Hudkins et al., 1993) with NMDA receptor antagonistic properties (Raveh et al., 1999; Figueiredo et al., 2011a), which has been shown previously to offer protection against nerve agent-induced seizures (Raveh et al., 2003, 2008; Figueiredo et al., 2011a) and neuropathology (Figueiredo et al., 2011a) in adult rats. Antagonism of NMDA receptors is particularly relevant to neuroprotection-as calcium influx via NMDA receptors plays a primary role in excitotoxic neuronal death (Portera-Cailliau et al., 1997; Liu et al., 2007; Fujikawa, 2015)_and it may be even more crucial in young subjects, when NMDA receptor activity is exceptionally high (Johnston, 1994).

\section{Materials and Methods}

Animals. Sprague-Dawley male rats (Charles River Laboratories, Wilmington, MA), 21 days old (P21; 50-60 g body weight at the time of soman exposure) were housed in an environmentally controlled room $\left(20-23^{\circ} \mathrm{C}, 12\right.$-hour light/12-hour dark cycle, lights on 06:00 $\left.\mathrm{AM}\right)$ in groups of five with a surrogate mother. Food and water were available ad libitum. The rats were weaned on the day of the experiments. Experiments were conducted according to the Guide for the Care and Use of Laboratory Animals (Institute of Laboratory Animal Resources, National Research Council) and were approved by the Institutional Animal Care and Use Committees of the U.S. Army Medical Research Institute of Chemical Defense and the Uniformed Services University of the Health Sciences. We used P21 rats because we are interested in the applicability of the findings to the pediatric population. P21 rats would correspond to about a 6-month-old human if we use the conversion factor for the early developmental phase (Andreollo et al., 2012; Sengupta, 2013). Because the developmental stage of the brain in the two species must be considered (Andersen, 2003), and synaptogenesis-which is a basic parameter of brain development-is completed within the first 3 weeks of life in rats and in about 3.5 years in humans (Pressler and Auvin, 2013), a P21 rat would correspond to a human close to 4 years of age.

Drug Administration and Seizure Assessment. Soman (pinacolyl methylphosphonofluoridate; obtained from the U.S. Army Edgewood Chemical Biologic Center, Aberdeen Proving Ground, MD) was diluted in cold saline and administered to P21 rats via a single subcutaneous injection at the dose of $74.4 \mu \mathrm{g} / \mathrm{kg}$, which corresponds to $1.2 \times \mathrm{LD}_{50}$ (Miller et al., 2015). To minimize the peripheral effects of soman, the rats were injected i.m. with $0.5 \mathrm{mg} / \mathrm{kg}$ atropine sulfate (Vedco Inc., St. Joseph, MO) and $125 \mathrm{mg} / \mathrm{kg} \mathrm{1-(2-}$ hydroxyiminomethylpyridinium)-3-(4-carbamoylpyridinium)-2oxapropane dichloride (HI-6, i.p.; Starks Associates, Buffalo, NY) within 1 minute after soman injection. The soman-exposed rats were randomly divided into four treatment groups, which, at 60 minutes after soman exposure, received $15 \mathrm{mg} / \mathrm{kg}$ LY293558 (provided by Raptor Pharmaceutical Corp., Novato, CA), 10 mg/kg DZP (Hospira Inc., Lake Forest, IL), $50 \mathrm{mg} / \mathrm{kg}$ CRM edisylate (Sigma-Aldrich, St Louis, MO), or the combination of $15 \mathrm{mg} / \mathrm{kg} \mathrm{LY} 293558$ and $50 \mathrm{mg} / \mathrm{kg}$ CRM. All anticonvulsants were injected intramuscularly because this would be the administration route in convulsing humans. Control animals received saline instead of soman and were not injected with any anticonvulsant. Seizures were monitored behaviorally and classified according to a minimally modified version of the Racine scale (Racine, 1972), as we have previously described (Figueiredo et al., 2011b): stage 0, no behavioral response; stage 1, behavioral arrest; stage 2, oral/facial movements, chewing, head nodding; stage 3, unilateral/bilateral forelimb clonus without rearing, Straub tail, extended body posture; stage 4 , bilateral forelimb clonus plus rearing; stage 5, rearing and falling; and stage 6, full tonic seizures. After soman injection, rats that went on to develop stage 3 seizures or above were considered to have SE.

Fixation and Tissue Processing. Neuropathological analysis was performed in the amygdala, piriform cortex, and CA1, CA3 and hilar areas of the ventral hippocampus 30 days after soman exposure; we study neurodegeneration in the ventral hippocampus because we have seen previously that it displays significantly more severe neurodegeneration after soman exposure than the dorsal hippocampus 
(Apland et al., 2010). Thirty days after soman administration, rats were deeply anesthetized with pentobarbital ( $75-100 \mathrm{mg} / \mathrm{kg}$, i.p.) and transcardially perfused with phosphate-buffered saline (PBS, $100 \mathrm{ml}$ ), followed by $4 \%$ paraformaldehyde $(200 \mathrm{ml})$. The brains were removed and postfixed overnight at $4^{\circ} \mathrm{C}$, then transferred to a solution of $30 \%$ sucrose in PBS for 72 hours, and frozen with dry ice before storage at $80^{\circ} \mathrm{C}$ until sectioning. A 1-in-5 series of sections from the rostral extent of the amygdala to the caudal extent of the entorhinal cortex was cut at $40 \mu \mathrm{m}$ on a sliding microtome. One series of sections was mounted on slides (Superfrost Plus; Daigger, Vernon Hills, IL) in PBS for Nissl staining with cresyl violet. Adjacent series of sections were mounted on slides for Fluoro-Jade C (FJC) staining. All neuropathological analysis was done in a blind fashion.

Fluoro-Jade C Staining and Analysis. FJC (Histo-Chem, Jefferson, AR) was used to identify irreversibly degenerating neurons in all the amygdalar nuclei and the piriform cortex $(-2.04$ to $-3.36 \mathrm{~mm}$ from bregma), as well as the CA1, CA3, and hilar areas of the ventral hippocampus ( -5.4 and $-6.36 \mathrm{~mm}$ from bregma; all coordinates from Paxinos and Watson, 2005). The procedure used has been described in detail in previous reports (Figueiredo et al., 2011a,b; Apland et al., 2014). Assessment of neurodegeneration was performed by superimposing the FJC-stained sections onto tracings of the regions of interest from a series of adjacent Nissl-stained sections using the Stereo Investigator 9.0 (MicroBrightField, Williston, VT). The rating scale used to score the extent of neuronal degeneration in each structure was as follows: $0=$ no damage, $1=$ minimal damage $(1 \%-$ $10 \%), 2=$ mild damage $(11 \%-25 \%), 3=$ moderate damage $(26 \%-45 \%)$, and $4=$ severe damage $(>45 \%)$. In a previous study, we have demonstrated that results from qualitative assessment using this scale are in agreement with results from quantitative assessments (Qashu et al., 2010). Neurodegeneration scores were assigned as percent of damaged tissue, considering the density of cells from Nisslstained sections in comparison with the density of the FJ-C stained cells, along the anterior to posterior extent, at $600-\mu \mathrm{m}$ intervals. Qualitative assessments were made from six sections per animal, and the average for each animal was recorded.

Volumetric Analysis. Volumetric analysis was performed 30 days after soman exposure. Nissl-stained sections containing the amygdala (sections were $200 \mu \mathrm{m}$ apart) or the hippocampus (sections were $400 \mu \mathrm{m}$ apart) were used to estimate stereologically the volume of these structures based on the previously described Cavalieri principle (Gundersen et al., 1999). Sections were viewed with a Zeiss Axioplan 2ie fluorescent microscope (Oberkochen, Germany) equipped with a motorized stage and interfaced with a computer running StereoInvestigator 9.0. The amygdala and the hippocampus were identified on slide-mounted sections under a $2.5 \times$ objective, based on the atlas of Paxinos and Watson (Paxinos and Watson, 2005), and traced using Stereo Investigator 9.0; coordinates used for the amygdala were from bregma -2.6 to bregma -3.6 ; coordinates used for the hippocampus were from bregma -2.3 to bregma -6.3 . The volume was calculated using the stereological probe called Cavalieri estimator. An overlay of a rectangular lattice with a grid size of $300 \mu \mathrm{m}$ was placed over the tracings of the amygdala and the hippocampus, and each point marked was counted to estimate the volume. For each animal, the coefficient of error (CE) was calculated to ensure sufficient accuracy of the estimate $(\mathrm{CE}<0.05)$.

Electrophysiologic Experiments. Thirty days after soman exposure, animals were decapitated after anesthesia with 3\%-5\% isoflurane. Coronal brain slices (400 $\mu \mathrm{m}$ thick) containing the amygdala ( -2.64 to -3.36 from bregma) were cut using a vibratome (Leica VT 1200 S; Leica Microsystems, Buffalo Grove, IL) in ice-cold cutting solution consisting of (in millimolars): 115 sucrose, $70 \mathrm{~N}$ methyl- $d$-glucamine, $1 \mathrm{KCl}, 2 \mathrm{CaCl}_{2}, 4 \mathrm{MgCl}_{2}, 1.25 \mathrm{NaH}_{2} \mathrm{PO}_{4}$, $30 \mathrm{NaHCO}_{3}$. The slices were transferred to a holding chamber, at room temperature, in a bath solution containing (in millimolars): $125 \mathrm{NaCl}, 2.5 \mathrm{KCl}, 1.25 \mathrm{NaH}_{2} \mathrm{PO}_{4}, 21 \mathrm{NaHCO}_{3}, 2 \mathrm{CaCl}_{2}, 1 \mathrm{MgCl}_{2}$, and $11 \mathrm{D}$-glucose. Recording solution was the same as the holding bath solution. All solutions were saturated with $95 \% \mathrm{O}_{2} / 5 \% \mathrm{CO}_{2}$ to achieve a pH near 7.4. The recording chamber (0.7-ml capacity) had continuously flowing artificial cerebrospinal fluid ( $\sim 6-8 \mathrm{ml} / \mathrm{min})$ at temperature of 32 to $33^{\circ} \mathrm{C}$. The osmolarity of this external solution was adjusted to $325 \mathrm{mOsm}$ with D-glucose.

Whole-cell recordings were obtained from neurons visualized under infrared light using Nomarski optics of an upright microscope (Axioskop 2; Zeiss, Thornwood, NY) through a $40 \times$ water immersion objective, equipped with a CCD-100 camera (Dage-MTI, Michigan City, IN). The patch electrodes had resistances of 3.5-4.5 $\mathrm{M} \Omega$ when filled with the internal solution (in millimolars): $60 \mathrm{CsCH}_{3} \mathrm{SO}_{3}$, $60 \mathrm{KCH}_{3} \mathrm{SO}_{3}, 5 \mathrm{KCl}, 10$ EGTA, 10 HEPES, $5 \mathrm{Mg}$-ATP, $0.3 \mathrm{Na}_{3} \mathrm{GTP}$ ( $\mathrm{pH}$ 7.2), 295 mOsm. Tight-seal (>1 G $\Omega$ ) whole-cell recordings were obtained from the cell body of pyramidal neurons in the basolateral nucleus of the amygdala (BLA) region and identified based on their electrophysiological properties (Sah et al., 2003; Park et al., 2007). Access resistance (15-24 M $\Omega$ ) was regularly monitored during recordings, and cells were rejected if the resistance changed by more than 15\% during the experiment. The Axopatch 200B amplifier (Axon Instruments, Foster City, CA) with a four-pole, low-pass Bessel filter, was used to amplify and filter (at $1 \mathrm{kHz}$ ) ionic currents and action potentials; the pClamp 10.5 software (Molecular Devices, Sunnyvale, $\mathrm{CA}$ ) was used to digitally sample (up to $2 \mathrm{kHz}$ ) the signals, which were further analyzed using the Mini Analysis program (Synaptosoft Inc., Fort Lee, NJ) and Origin (OriginLab Corporation, Northampton, MA), as described previously (Pidoplichko et al., 2014). The charge transferred by postsynaptic currents was calculated using the Mini60 software by Synaptosoft.

Behavioral Experiments. Behavior in the open field and responses to acoustic startle were examined 30 days after soman exposure. In the open-field apparatus $(40 \times 40 \times 30 \mathrm{~cm}$ clear Plexiglas arena), anxiety-like behavior was assessed as described previously (Aroniadou-Anderjaska et al., 2012; Prager et al., 2015). One day before testing (on day 29 after soman exposure), animals were acclimated to the apparatus for 20 minutes. On the test day, the rats were placed in the center of the open field, and activity was measured and recorded for 20 minutes using an Accuscan Electronics infrared photocell system (Accuscan Instruments Inc., Columbus, OH). Data were automatically collected and transmitted to a computer equipped with Fusion software (from Accuscan Electronics). Locomotion (distance traveled in $\mathrm{cm}$ ), total movement time, and time spent in the center of the open field were analyzed. Anxiety-like behavior was measured as the ratio of the time spent in the center over the total movement time, expressed as a percentage of the total movement time.

Acoustic startle response testing was conducted with the use of the Med Associates Acoustic Response Test System (Med Associates, Georgia, VT), which consists of weight-sensitive platforms inside individual sound-attenuating chambers. A ventilating fan built into the chamber provides background noise. Each rat was individually placed in a ventilated holding cage. The holding cages are small enough to restrict extensive locomotion but large enough to allow the subject to turn around and make other small movements. Each cage was placed on a weight-sensitive platform. Subjects' movements in response to stimuli were measured as a voltage change by a strain gauge inside each platform. All animals were acclimated to the apparatus in two sessions on post-soman days 28 and 29. Startle stimuli consisted of $110-$ or $120-\mathrm{dB}$ noise bursts (burst duration 20 milliseconds). Each stimulus had a 2-millisecond rise and decay time, such that the onset and offset were abrupt, which is a primary requirement for startle. Each trial type (110- or 120-dB stimulus) was presented eight times. Trial types were presented in random order to avoid effects and habituation, and intertrial intervals ranged randomly from 15 to 25 seconds. Responses were recorded by an interfaced Pentium computer as the maximum response occurring during the no-stimulus periods and during the startle period, and were assigned a value based on an arbitrary scale used by the software of the test system.

Statistical Analysis. Fisher's exact test was used to compare the survival rate between the groups. Differences between groups in 


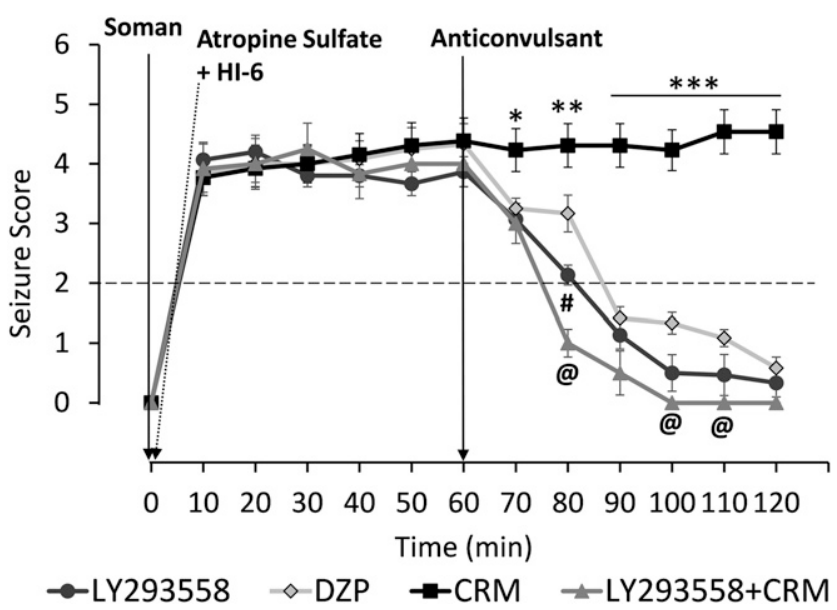

Fig. 1. Time course of seizure suppression by the anticonvulsant treatments after soman exposure: fastest suppression by the LY293558 + CRM combination treatment. LY293558, DZP, CRM, or LY293558 + CRM were administered 1 hour after injection of soman. The combination treatment of LY293558 + CRM effected the fastest suppression of seizures; the behavioral seizure score in this group was significantly lower than the score in the LY293558 group and the DZP group 20 minutes after anticonvulsant administration $(P<0.05)$ and lower than the score in the DZP group 40 and 50 minutes after administration $(P<0.05)$. Seizure scores in the CRM group were significantly higher than the scores in all other three groups at all time points. $* P<0.05 ; * * P<0.01$; $* * * P<0.001$ compared with each of the three other groups. ${ }^{\circledR} P<0.05$ comparing the LY293558 + CRM group with the DZP group. ${ }^{\#} P<0.05$ comparing the LY293558 + CRM group with the LY293558 group.

latency to seizure termination, as well as in seizure score at different time points after soman exposure were tested for significance using one-way analysis of variance, followed by least significant difference post-hoc test. Neurodegeneration scores were compared between groups for each structure separately using the Kruskal-Wallis test followed by MannWhitney $U$ test for comparisons between pairs of groups. Statistical values for neurodegeneration scores are presented as median and the interquartile range (IQR, the difference between the 75th and the 25th percentiles). Data from electrophysiological recordings were also analyzed using the Kruskal-Wallis test, followed by the Mann-Whitney $U$ test for comparisons between pairs of groups. Data from the volumetric analysis, and differences between groups in the behavioral parameters were tested for significance using analysis of variance followed by least significant difference post-hoc tests; statistical values are presented as mean and standard error of the mean. For all tests, differences were considered significant when $P<0.05$. Sample sizes $(n)$ refer to the number of animals, except for the in vitro experiments, where it refers to the number of recorded neurons.

\section{Results}

Antilethality and Anticonvulsant Efficacy of the Treatments. Soman-exposed rats were randomly assigned into groups that received LY293558 as an anticonvulsant treatment $(n=40)$, DZP $(n=14)$, CRM $(n=65)$, or the combination of CRM and LY293558 $(n=40)$. Anticonvulsant treatments were administered 1 hour after soman injection. Survival rate for the LY293558-treated group was $87.5 \%$, for the DZP-treated group $85.7 \%$ (no significant difference from the LY293558-treated group or the LY293558 + CRM group, $P>0.05)$, for the CRM-treated group $64.6 \%(P<0.05$, significantly lower compared with the LY293558-treated group; $P<0.001$, significantly lower compared with the LY293558 + CRM group; no significant difference from the DZP group, $P=0.21$ ), and for the LY293558 + CRM-treated group survival rate was $95 \%$. All anticonvulsant treatments stopped SE (behavioral seizure score stage 2 or lower), except for CRM when administered alone. The latency to cessation of SE was $25 \pm 3$ minutes in the LY293558 group, $30 \pm 5$ minutes in the DZP group, and $13 \pm 4$ minutes in the LY293558 + CRM group $(P<0.05$, in comparison with the LY293558 or the DZP groups). These results are summarized in Table 1; Fig. 1 shows the time course of the effect of the four anticonvulsant treatments on behavioral seizure scores.

Efficacy of the Anticonvulsant Treatments in Preventing Brain Damage. Neurodegeneration was present 1 month postexposure; it was more pronounced in the groups that were treated with DZP or CRM alone and absent in the group that was treated with LY293558 + CRM (Fig. 2). Thus, in the amygdala, neurodegeneration was mild in the LY293558-treated group (median $=2, \mathrm{IQR}=2 \sim 3 ; n=14$ ), moderate in the DZP group (median $=3.5, \mathrm{IQR}=2.5 \sim 3.5 ; n=$ 12; $P=0.06$ compared with the LY293558 group), severe in the CRM group (median $=4$, IQR $=3 \sim 4 ; n=18 ; P<0.05$ compared with the LY293558 group), and absent in the LY293558+CRM group (median $=0, \mathrm{IQR}=0 \sim 0 ; n=18$; $P<0.001$, significantly lower compared with all other three groups). In the piriform cortex, neurodegeneration was minimal in the LY293558 and DZP groups (median $=1, \mathrm{IQR}=$ $1 \sim 2$ ), moderate in the CRM group (median $=3, \mathrm{IQR}=3 \sim 3$; $P<0.05$ compared with either the LY293558 or the DZP group), and absent in the LY293558 + CRM group (median $=$ $0, \mathrm{IQR}=0 \sim 0 ; P<0.01$ compared with all other three groups). In the CA1 hippocampal area, neurodegeneration was mild in the LY293558-treated group (median $=2, \mathrm{IQR}=2 \sim 3$ ), severe in the DZP group (median $=4, \mathrm{IQR}=3 \sim 4 ; P<0.05$ compared with the LY293558 group), moderate in the CRM group (median $=3.5, \mathrm{IQR}=3 \sim 4 ; P<0.05$ compared with the LY293558 group), and absent in the LY293558+CRM group (median $=0, \mathrm{IQR}=0 \sim 0 ; P<0.001$ compared with all other three groups). In the CA3 hippocampal area, neurodegeneration was mild in the LY293558-treated group (median $=2$, $\mathrm{IQR}=2 \sim 3$ ), severe in the DZP group (median $=4, \mathrm{IQR}=3 \sim 4$; $P<0.05$ compared with the LY293558 group), severe in the CRM group (median $=4$, IQR $=3.25 \sim 4 ; P<0.05$ compared

TABLE 1

Survival rate and latency to cessation of SE in groups of soman-exposed rats treated with LY293558, DZP, CRM, or LY293558 + CRM at 1 hour after soman injection

\begin{tabular}{lcccr}
\hline & LY293558 & DZP & CRM & LY293558+CRM \\
\hline Survival rate (no. of rats) & $87.5 \%(35 / 40)$ & $85.7 \%(12 / 14)$ & $64.6 \%(42 / 65) * * * *$ & $95 \%(38 / 40)$ \\
Cessation of SE (no. of rats) & $100 \%(40 / 40)$ & $100 \%(14 / 14)$ & $0(0 / 65)$ & $100 \%(40 / 40)$ \\
Latency to cessation of SE & $25 \pm 3 \mathrm{~min}$ & $30 \pm 5 \mathrm{~min}$ & - & $13 \pm 4 \mathrm{~min}^{\#}$ \\
\hline
\end{tabular}

${ }^{*} P<0.05$ compared with the LY293558 group; $* * * P<0.001$ compared with the LY293558 + CRM group; ${ }^{*} P<0.05$ compared with either the LY293558 or the DZP groups. 

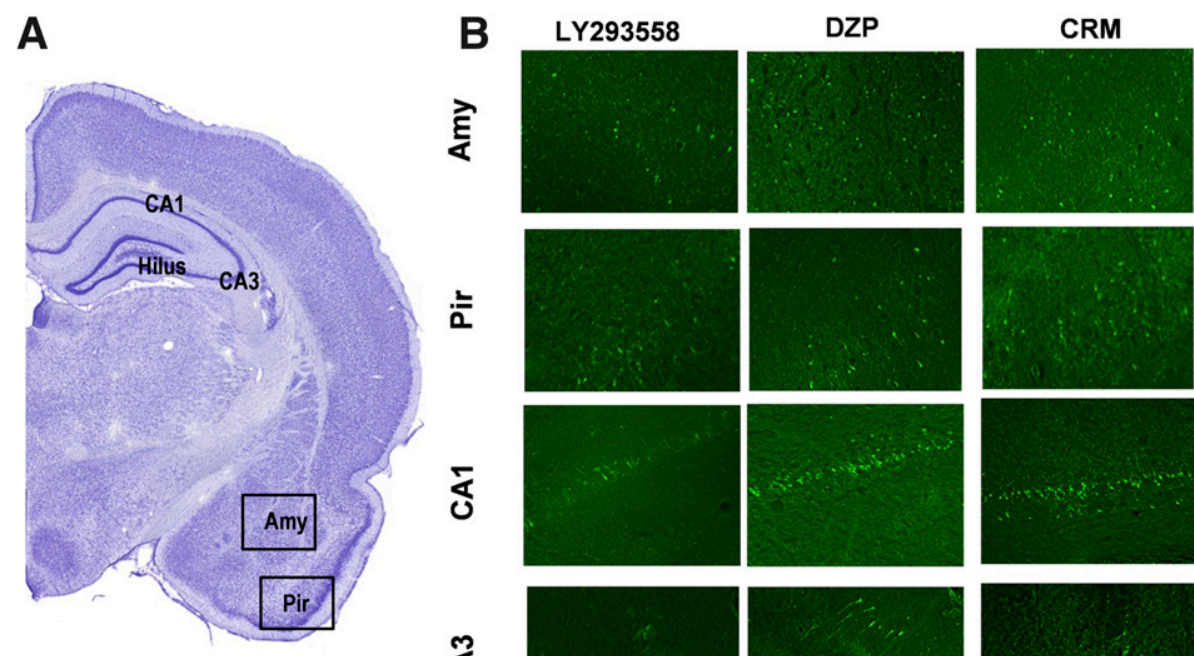

LY293558+CRM
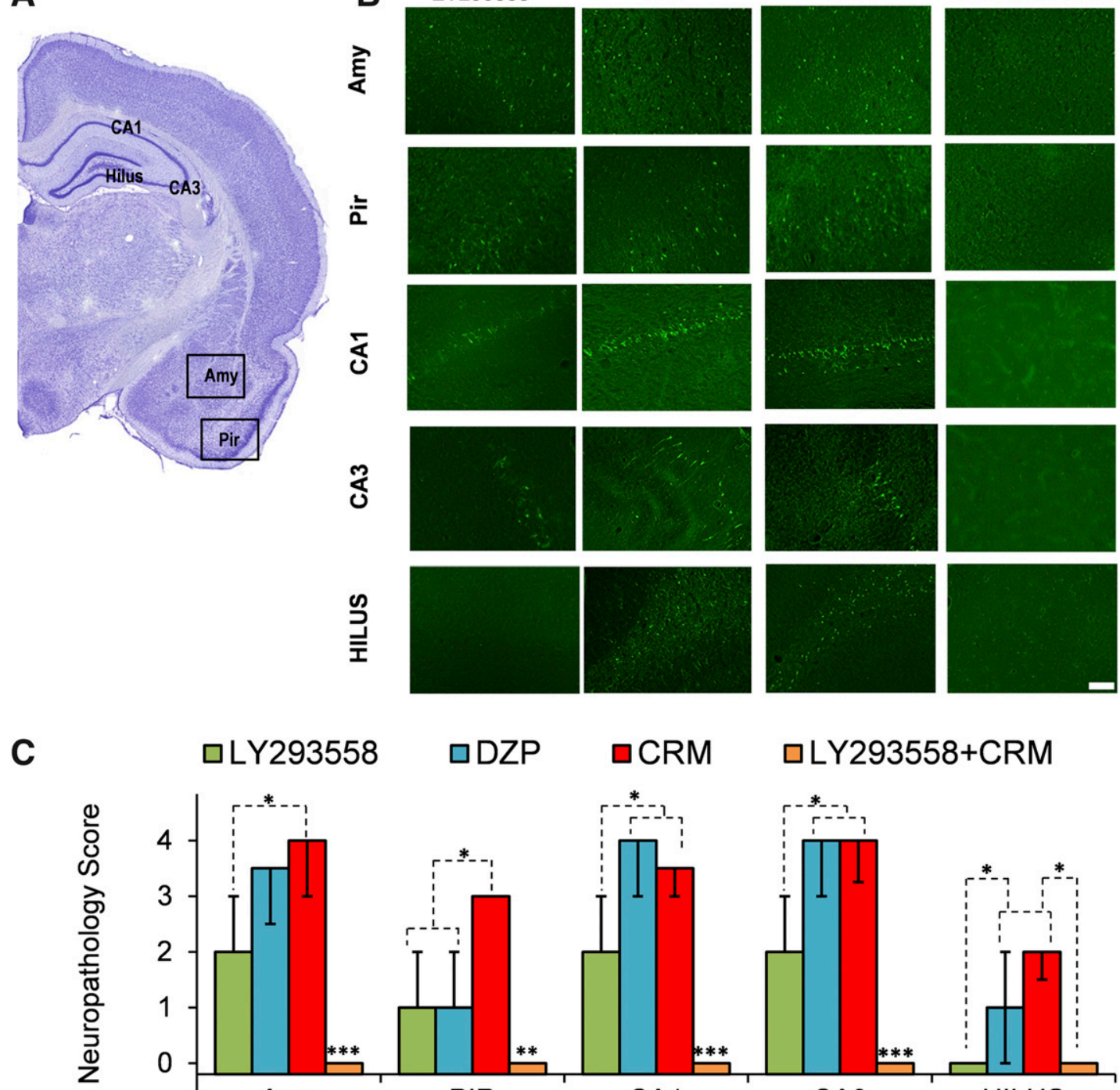

口LY293558+CRM

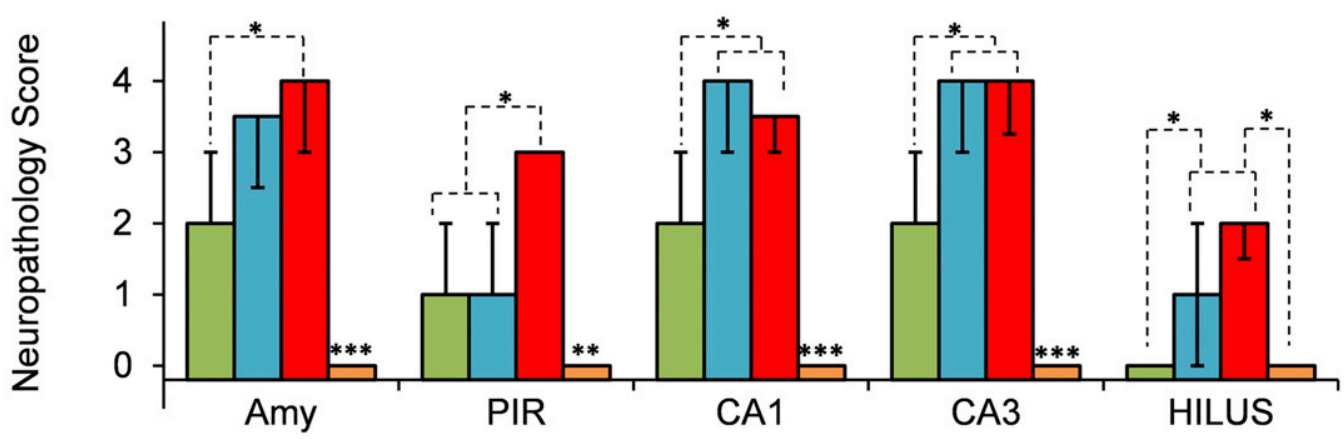

Fig. 2. Efficacy of the anticonvulsant treatments in preventing neuronal degeneration in the amygdala and the hippocampus: complete protection provided by the LY293558 + CRM combination treatment. Neuronal degeneration was evaluated 30 days after exposure to soman. (A) Panoramic photomicrograph of a Nissl-stained section showing the brain regions evaluated by FJC staining. (B) Representative photomicrographs of FJC-stained sections from the amygdala, piriform cortex, and hippocampal regions for the LY293558, DZP, CRM, and LY293558 + CRM groups. Total magnification is $100 \times$. Scale bar, $50 \mu \mathrm{m}$. (C) Neuropathology scores (median and interquartile range) for the four groups. $* P<0.05$ comparing the CRM group $(n=18)$ with the LY293558 group $(n=14)$, in the amygdala comparing the CRM group with either the LY293558 or the DZP group ( $n=12)$, in the piriform cortex comparing the CRM or the DZP group with the LY293558 group in the CA1 and CA3 hippocampal regions, and comparing the CRM or the DZP group with either the LY293558 or the LY293558 + CRM group $(n=18)$ in the hippocampal hilus. ** $P<0.01 ; * * * P<0.001$ comparing the LY293558 + CRM group with each of the three other groups.

with the LY293558 group), and absent in the LY293558+CRM group (median $=0$, IQR $=0 \sim 0 ; P<0.001$ compared with all other three groups). Finally, in the hilus of the hippocampus, neurodegeneration was absent in the LY293558-treated group (median $=0, \mathrm{IQR}=0 \sim 0$ ), minimal in the DZP group (median $=1, \mathrm{IQR}=0 \sim 2$ ), moderate in the CRM group (median $=2, \mathrm{IQR}=0.5 \sim 2$ ), and absent in the LY293558 + CRM group (median $=0, \mathrm{IQR}=0 \sim 0$ ); in both LY293550 alone and LY293558 + CRM groups, neurodegeneration in the hilus was significantly lower than that in the DZP and CRM groups $(P<0.05)$.

Since exposure to soman causes reduction in the amygdala and hippocampal volumes (Miller et al., 2015), we compared the efficacies of the anticonvulsant treatments in preventing this pathology. Thirty days after soman exposure, amygdala volume in the LY293558-treated rats $\left(12.13 \pm 0.2 \mathrm{~mm}^{3}, n=8\right)$ was not significantly different from that in the control (not exposed to the soman) group $\left(12.48 \pm 0.3 \mathrm{~mm}^{3}, n=8 ; P=0.29\right.$; Fig. 3). Similarly, amygdala volume in the LY293558 + CRM-treated group $\left(12.2 \pm 0.3 \mathrm{~mm}^{3}, n=8\right)$ did not differ from that in the control group $(P=0.12)$. In contrast, amygdala volumes in the DZP group $\left(10.2 \pm 0.2 \mathrm{~mm}^{3}, n=8\right)$ and the CRM group $\left(9.87 \pm 0.5 \mathrm{~mm}^{3}, n=8\right)$ were significantly smaller compared with the control group $(P<0.01)$, the LY293558 group $(P<0.01)$, or the LY293558 + CRM group $(P<0.05$; Fig. 3). Hippocampal volume in the LY293558treated rats $\left(61.85 \pm 0.5 \mathrm{~mm}^{3}, n=8\right)$ was not significantly different from that in the control group $\left(65.8 \pm 0.8 \mathrm{~mm}^{3}, n=8\right.$; 

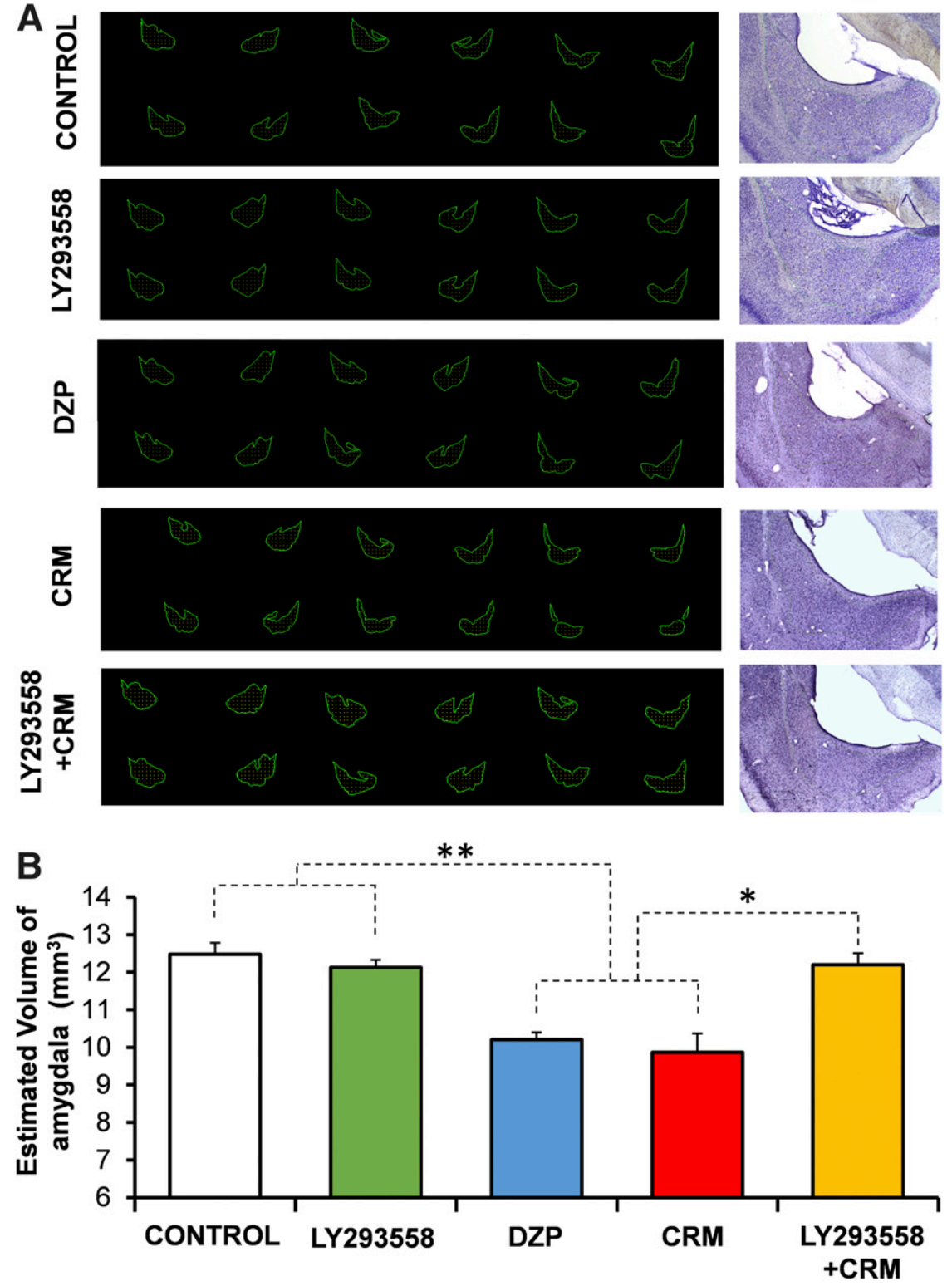
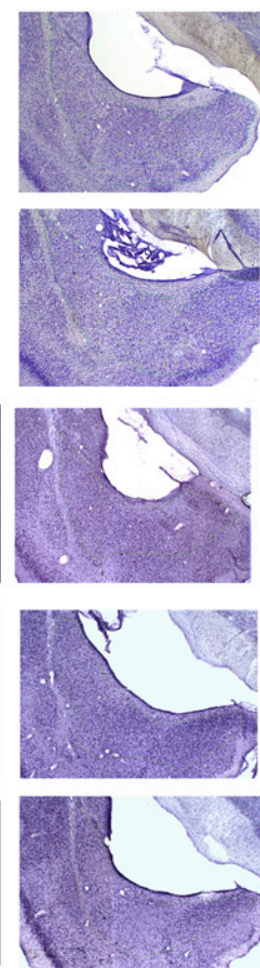

Fig. 3. Efficacy of the anticonvulsant treatments in preventing reduction in amygdala volume: protection provided only by the LY293558 and the LY293558 + CRM treatments. Volumetric analysis was performed 30 days after soman exposure using the Cavalieri principle (see Materials and Methods section for details). (A) Representative tracings of the amygdala from bregma -2.6 to bregma -3.6 in a series of sections $200 \mu \mathrm{m}$ apart (left) and corresponding photomicrographs of ventral amygdala and adjacent areas taken around bregma -3.6 (right) from the control (not exposed to soman) group and from the four treatment groups. (B) Group data showing the estimated volume of the amygdala $(n=8$ in each group). ${ }^{*} P<0.05$ comparing the DZP or the CRM group with the LY293558 + CRM group. ** $P<0.01$ comparing the DZP or the CRM group with the control or the LY293558 group.
$P=0.78$; Fig. 4). Hippocampal volume in the LY293558+ CRM-treated group $\left(63.18 \pm 0.8 \mathrm{~mm}^{3}, n=8\right)$ also did not differ from that in the control group $(P=0.85)$. In contrast, hippocampal volumes in the DZP group $\left(56.2 \pm 0.7 \mathrm{~mm}^{3}\right.$, $n=8)$ and the CRM group (50.48 $\left.\pm 0.6 \mathrm{~mm}^{3}, n=8\right)$ were significantly smaller compared with the control group $(P<$ $0.001)$, the LY293558 group $(P<0.05)$, or the LY293558+ CRM group $(P<0.01)$; in the CRM group, hippocampal volume was also significantly smaller than that in the DZP group ( $P<0.05$; Fig. 4).

Efficacy of the Anticonvulsant Treatments in Preventing Pathophysiologic Alterations in the Basolateral Amygdala. The amygdala is central to emotional behavior (Phelps and LeDoux, 2005), and its dysfunction is at the root of a host of neuropsychiatric disorders. Amygdala hyperexcitability is a characteristic feature of anxiety disorders (Anand and Shekhar, 2003; Etkin and Wager, 2007; Stein and Stein, 2008; Aroniadou-Anderjaska, 2015), and hyperexcitability in the basolateral nucleus of the amygdala (BLA) in particular is associated with increased anxiety-like behavior in animals (Sajdyk and Shekhar, 1997; Vazdarjanova et al., 2001; Shekhar et al., 2003; Wang et al., 2011; AroniadouAnderjaska et al., 2012; Pidoplichko et al., 2014). GABAergic control of the excitability of the BLA network appears to be particularly powerful (Rainnie, 1999; Muller et al., 2005; Pan et al., 2009; Popescu and Pare, 2011), and we have shown previously that it is severely compromised after exposure to soman (Prager et al., 2014), along with an increase in anxietylike behavior (Prager et al., 2015). Therefore, in the present study, we compared the efficacy of the anticonvulsant treatments in preventing the decrease in spontaneous inhibitory activity caused by soman exposure.

Most principal neurons in the BLA of control (not exposed to soman) rats (7 of 10 neurons) displayed rhythmic "bursts" of summated spontaneous induced pleuripotent stem cells (sIPSCs), as observed previously by others (Rainnie, 1999; Chung and Moore, 2009; Ohshiro et al., 2011; Popescu and Paré, 2011). Thirty days after soman exposure, bursts of 

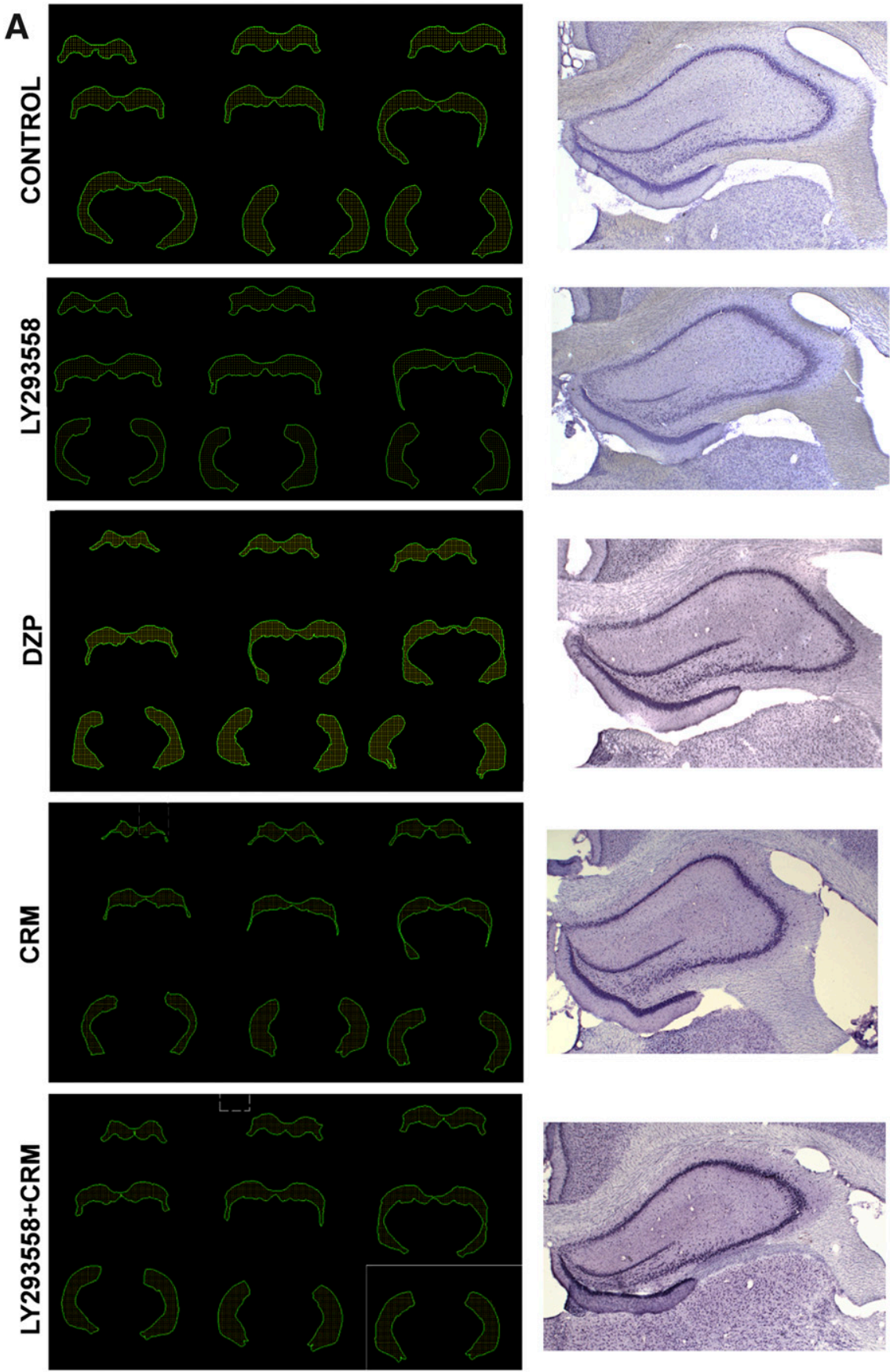

B

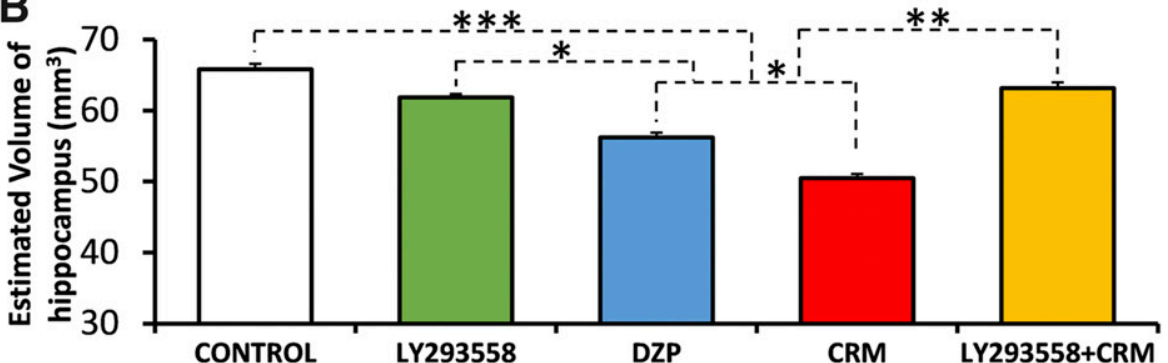

Fig. 4. Efficacy of the anticonvulsant treatments in preventing reduction in hippocampal volume: protection provided only by the LY293558 and the LY293558 + CRM treatments. Volumetric analysis was performed 30 days after soman exposure using the Cavalieri principle (see Materials and Methods section for details). (A) Representative tracings of the hippocampus from bregma -2.3 to bregma -6.3 in a series of sections $400 \mu \mathrm{m}$ apart (left) and corresponding photomicrographs of dorsal hippocampus and adjacent areas taken around bregma -2.3 (right) from the control (not exposed to soman) group and from the four treatment groups. (B) Group data showing the estimated volume of the hippocampus ( $n=8$ in each group). ${ }^{*} P<0.05$ comparing the CRM with the DZP group, and the CRM or DZP group with the LY293558 group. $* * P<0.01$ comparing the DZP or the CRM group with the LY293558 + CRM group. $* * * P<0.001$ comparing the DZP or the CRM group with the control group.
sIPSCs were also present in recordings from BLA principal cells in rats treated with LY293558 (four of eight neurons displayed sIPSC bursts) or LY293558 + CRM (7 of 13 neurons displayed sIPSC bursts). In contrast, sIPSC bursts were not present in BLA neurons recorded from DZP-treated rats (zero of eight neurons) or CRM-treated rats (zero of eight neurons). Representative examples are shown in Fig. 5A. To quantify these differences among groups, we calculated the total charge 
A

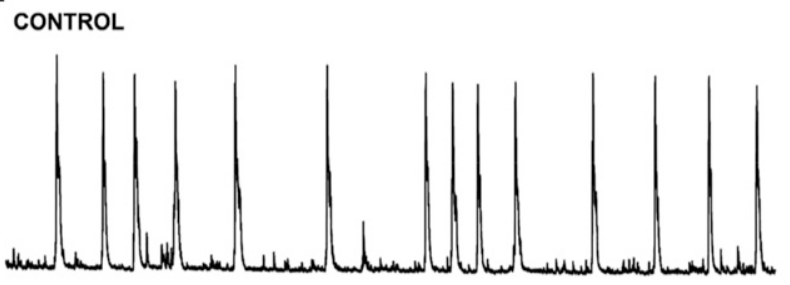

LY293558

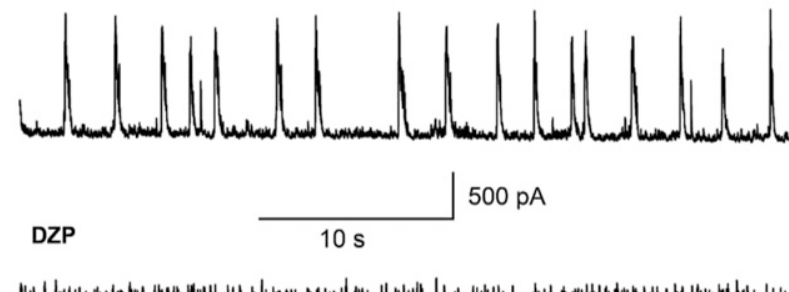

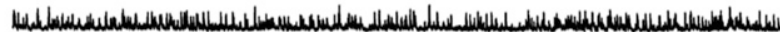

\section{CRM}

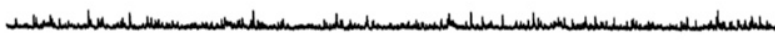

LY293558 + CRM

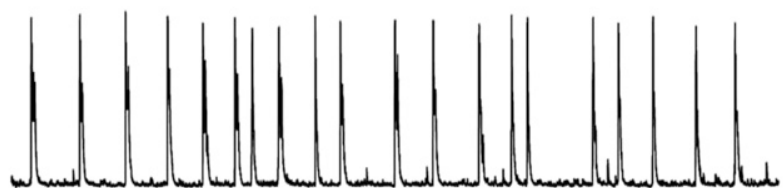

B

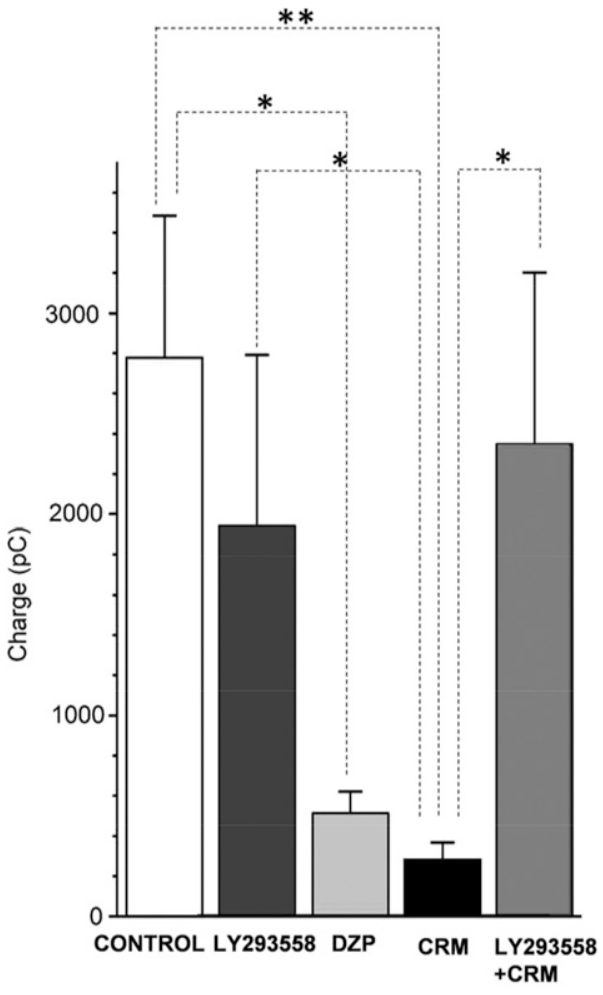

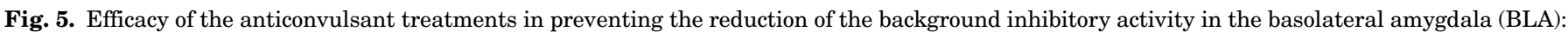

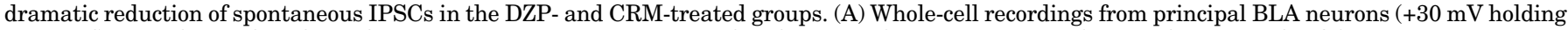

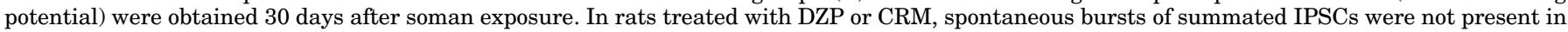

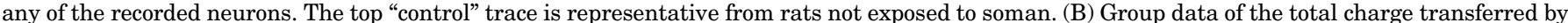

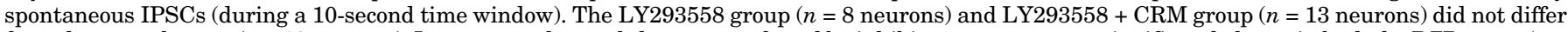

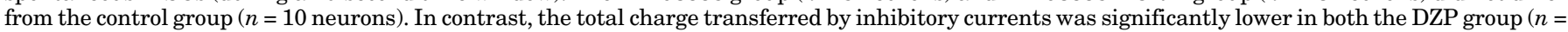

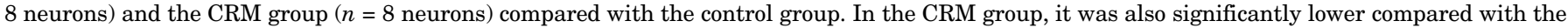
LY293558 or the LY293558 + CRM groups. ${ }^{*} P<0.05 ; * * P<0.01$.

transferred (the area delimited by the inhibitory current and the baseline), in pico Coulombs (pC), for a time window of 10 seconds; we included all recorded neurons in these comparisons, whether they generated rhythmic sIPSC bursts or displayed only conventional spontaneous inhibitory activity. The total charge transferred by sIPSCs in the LY293558 group (1940.31 $\pm 851.18 \mathrm{pC}, n=8)$ was not significantly different from that in the control group $(2778.04 \pm 708.11 \mathrm{pC}$, $n=10 ; P=0.105$; Fig. 5B). Similarly, the total charge transferred by sIPSCs in the LY293558 + CRM group $(2347.12 \pm 854.31, n=13)$ did not differ from the control $(P=0.268)$. In contrast, the total charge transferred by sIPSCs in the DZP group (512.1 $\pm 107.76 \mathrm{pC}, n=8)$ and the CRM group (282.55 $\pm 85.37 \mathrm{pC}, n=8)$ was significantly lower compared with the control $(P<0.05$ for the DZP group and $P<$ 0.01 for the CRM group). The total charge transferred by inhibitory currents in the CRM group was also significantly lower than that in the LY293558 group and the LY293558 + CRM group ( $P<0.05$ for both comparisons); other betweengroup comparisons were not statistically significant owing to the high variability produced by the presence or absence of the sIPSC bursts. These group data are depicted in Fig. 5B.

Efficacy of the Anticonvulsant Treatments in Preventing Increases in Anxiety-Like Behavior. Thirty days after exposure to soman, the anxiety level of rats in the different groups was examined in the open-field and the acoustic startle response tests. In the open-field test, the more anxious an animal is, the less time it spends in the center of the open field (Prut and Belzung, 2003). We found that the time spent in the center by the LY293558 group (88.4 \pm 12.4 seconds or $10.6 \% \pm 1.4 \%$ of the total movement time, $n=14$ ) or the LY293558 + CRM group (118 \pm 15 seconds or $13.7 \% \pm$ $6.0 \%$ of the total movement time, $n=18$ ) was not significantly different from the time spent in the center by the control (not exposed to soman) rats ( $102 \pm 7.9$ seconds or $12.9 \% \pm 1.0 \%$ of the total movement time, $n=12 ; P=0.180$ for the LY293558 group and $P=0.676$ for the LY293558 + CRM group). In contrast, the time spent in the center by the DZP group (54.8 \pm 5.9 seconds or $6.8 \% \pm 0.6 \%$ of the total movement time, $n=12$ ) or the CRM group $(56 \pm 11.3$ seconds or $6.7 \% \pm 1.3 \%$ of the total movement time, $n=18$ ) was significantly less compared with the control group $(P<0.01$ for the DZP group and $P<$ 0.001 for the CRM group), as well as with the LY293558 group $(P<0.05$ for both the DZP and the CRM groups) and the LY293558 + CRM group $(P<0.001$ for the DZP group and $P=$ 0.001 for the CRM group; Fig. 6A). The distance traveled by the LY293558 group ( $2542 \pm 166 \mathrm{~cm})$, the DZP group (2478 \pm $138 \mathrm{~cm})$, the CRM group $(2673 \pm 198)$, and the LY293558+ 

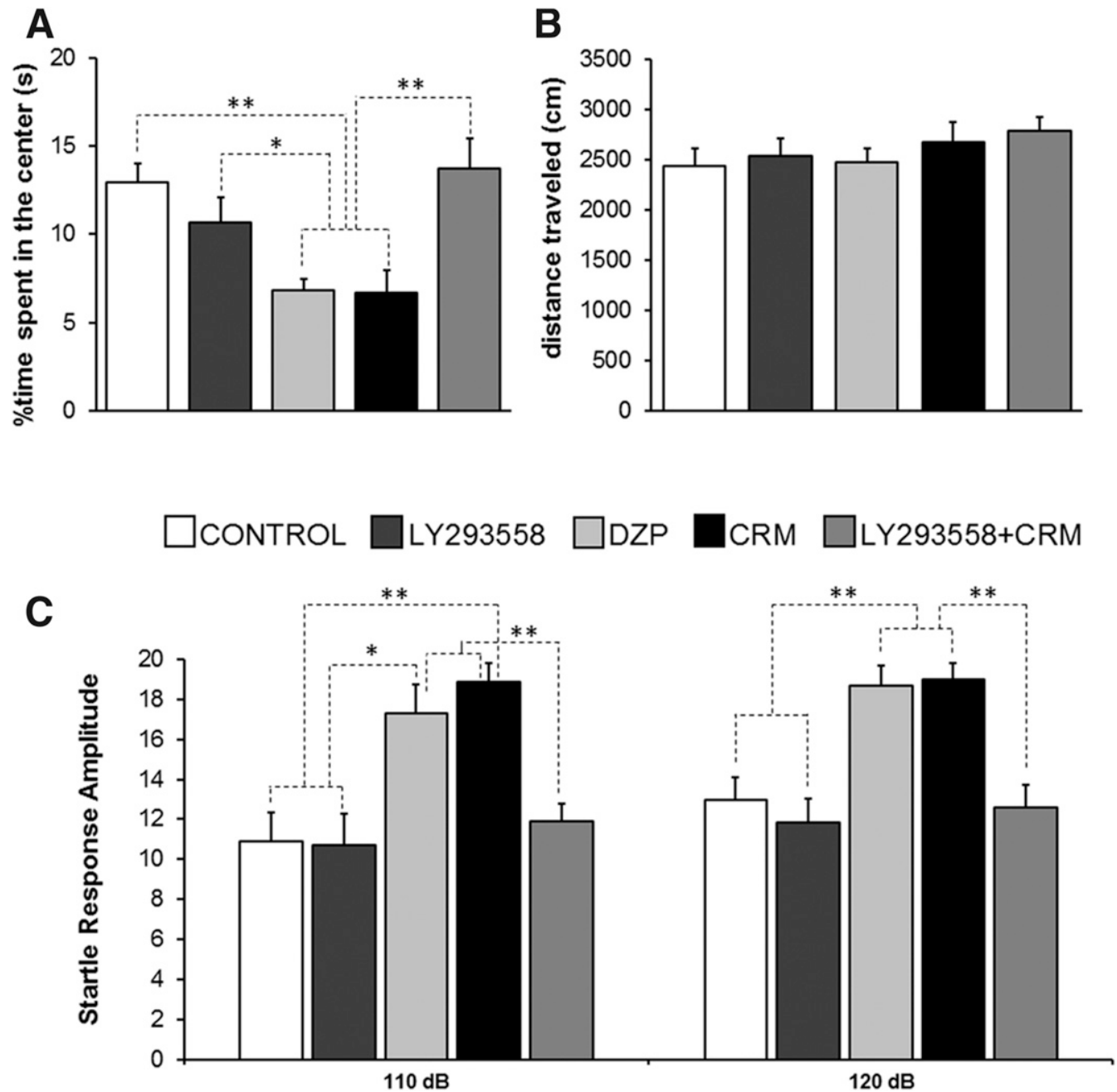

Fig. 6. Efficacy of the anticonvulsant treatments in preventing increases in anxiety-like behavior: increased anxiety in the groups treated with DZP or CRM. (A) Thirty days after exposure to soman, the rats treated with DZP $(n=12)$ or CRM $(n=18)$ spent significantly less time in the center of the open field compared with the time spent by the rats in the control (not exposed to soman) group $(n=12)$, the LY293558 group ( $n=14)$, or the LY293558 + CRM group $(n=18)$. The rats treated with LY293558 or LY293558+CRM did not differ from the controls in the time spent in the center. (B) The total distance traveled in the open field did not differ between the groups. (C) The amplitude of the startle response to 110 days (B, left panel) or 120 days (B, right panel) of acoustic stimuli was significantly increased in the DZP-treated group $(n=12)$ and the CRM group $(n=18)$ compared with the controls $(n=12)$, the LY293558 group $(n=14)$, or the LY293559 + CRM group $(n=18) * P<0.05 ; * * P<0.01$

CRM group $(2792 \pm 140 \mathrm{~cm})$ did not differ from the distance traveled by the control rats $(2441 \pm 171 \mathrm{~cm}$; Fig. $6 \mathrm{~B})$.

In the acoustic startle response test, the amplitude of the startle response to an acoustic stimulus is a reflection of the anxiety level of the animal (Li et al., 2009). In response to the 110-dB acoustic stimulus, the amplitude of the startle in the LY293558 group $(10.7 \pm 1.58, n=14)$ or the LY293558 + CRM group (11.89 $\pm 0.89, n=18)$ was not significantly different from the startle amplitude in the control group $(10.89 \pm 1.48, n=12$; $P=0.93$ for the LY293558 group and $P=0.74$ for the LY293558+CRM group). In contrast, the startle amplitude in the DZP group $(17.33 \pm 1.43, n=12)$ or the CRM group $(18.89 \pm$ $0.9, n=18$ ) was significantly greater compared with the control group or the LY293558 group $(P<0.05$ for the DZP group and $P<0.01$ for the CRM group), as well as the LY293558 + CRM group $(P<0.01$ for both the DZP and the CRM groups; Fig. $6 \mathrm{C}$, left panel). Similar results were obtained in response to the 120-dB acoustic stimulus. Thus, the amplitude of the startle in the LY293558 group $(11.89 \pm 1.22)$ or the LY293558 + CRM group $(12.6 \pm 1.12)$ was not significantly different from the startle amplitude in the control group $(12.99 \pm 1.12 ; P=0.62$ for the LY293558 group and $P=0.92$ for the LY293558 + CRM group). In contrast, the startle amplitude in the DZP group $(18.67 \pm 0.99)$ or the CRM group $(18.99 \pm 0.85)$ was significantly greater compared with controls, the LY293558, or the LY293558 + CRM group $(P<0.01$ for both the DZP and CRM groups; Fig. 6C, right panel).

\section{Discussion}

The present study showed that when LY293558, DZP, CRM, or LY293558 + CRM were administered 1 hour after acute exposure of P21 rats to a high dose of soman, LY293558, LY293558 + CRM, and DZP terminated the soman-induced SE, with the LY293558 + CRM combination acting with the fastest time course; CRM did not stop SE when administered alone. Evaluation of long-term effects, 30 days after soman exposure, showed that 1) LY293558 and LY293558 + CRM 
protected against neuronal degeneration, with the combination treatment providing full protection, in contrast to DZP, which did not protect the hippocampus, and CRM, which offered no neuroprotection; 2) both LY293558 and LY293558 + CRM, but not DZP or CRM, prevented amygdala and hippocampal atrophy; 3) both LY293558 and LY293558 + CRM, but not DZP or CRM, prevented the reduction of spontaneous inhibitory activity in the BLA; and 4) both LY293558 and LY293558 + CRM, but not DZP or CRM, prevented the development of anxiety.

Greater Neuroprotective Efficacy of LY293558 Compared with DZP in P21 Rats, as Previously Found in Adult Rats. DZP is the anticonvulsant currently approved by the FDA for terminating SE induced by nerve agent exposure, saving the lives of the victims. Indeed, the present study and previous studies (Shih and McDonough, 1999; de Araujo Furtado et al., 2010; McDonough et al., 2010; Langston et al., 2012; Todorovic et al., 2012; Apland et al., 2014) have shown that DZP can stop SE induced by nerve agents or other organophosphorus toxins and results in a high survival rate; however, not only the antiseizure efficacy of DZP is reduced as the latency of administration from the onset of SE lengthens (Shih and McDonough, 1999; McDonough et al., 2010; Todorovic et al., 2012), but, importantly, this compound does not protect against brain damage. DZP has been used in adult rat models of nerve agent exposure as a means to stop ongoing nerve agent-induced SE and then study neuropathology (e.g., de Araujo Furtado et al., 2010; Langston et al., 2012), suggesting that it is rather common knowledge that significant neuropathology will be found after DZP treatment. In these studies, SE is not allowed to continue for more than 1 hour before it is treated with DZP; yet, significant damage and/or long-term behavioral deficits can occur (de Araujo Furtado et al., 2010; Langston et al., 2012). In contrast, when LY293558 is administered after 1 hour of ongoing SE in soman-exposed adult rats, significant neuroprotection is achieved (Figueiredo et al., 2011b). In addition, when the efficacy of the specific GluK1R antagonist UBP302 was compared with that of DZP in soman-exposed adult rats, only UBP302 protected against neuropathology and behavioral deficits (Apland et al., 2014). Similarly to the results in these studies in adult rats, the present study in P21 rats showed that, in contrast to the efficacy displayed by LY293558, DZP provided little protection against neurodegeneration and did not prevent amygdala and hippocampal atrophy or the accompanying pathophysiologic and behavioral deficits.

It should be noted that another benzodiazepine, midazolam, is being tested as a possible better alternative to DZP (Capacio et al., 2004; McDonough et al., 2009; Reddy and Reddy, 2015). The data reported so far show that midazolam can protect against nerve agent-induced brain damage in adult or youngadult rats if it is administered at the time of exposure (Chapman et al., 2015), at the onset of seizures (RamaRao et al., 2014), or after 5 minutes of seizure activity (Gilat et al., 2005); however, if it is given 1 hour after exposure, it does not prevent histologic damage, despite its antiseizure efficacy and beneficial effects on behavioral performance and inflammatory responses (Chapman et al., 2015). More studies are needed to understand the neuroprotective efficacy of midazolam administered at different time points after nerve agent exposure, and direct comparisons must be made with LY293558 under the same experimental conditions for two drugs.

DZP Versus LY293558: Relating Mechanisms of Action to Neuroprotective Effects. The low neuroprotective efficacy of DZP may be related to the transient nature of its seizure-suppressing effects. Shih and McDonough (1999) reported that $25 \%$ of the animals receiving $9 \mathrm{mg} / \mathrm{kg}$ DZP 5 minutes after the onset of soman-induced seizures had seizures recurring within the 6-hour monitoring period, whereas in rats receiving $10 \mathrm{mg} / \mathrm{kg} \mathrm{DZP}$ at 1 hour after soman exposur,e we found recurrence of seizures in all animals, resulting in a total duration of SE within 24 hours after exposure that does not differ from that in rats receiving no anticonvulsant treatment (Apland et al., 2014). Although administration of DZP enhances GABAergic inhibition, thereby suppressing seizures, the function of the GABAergic system is weakened during seizure activity (Goodkin et al., 2005; Naylor et al., 2005; Deeb et al., 2012), and DZP itself may contribute to further desensitization and downregulation of $\mathrm{GABA}_{\mathrm{A}}$ receptors (Uusi-Oukari and Korpi, 2010; Vinkers and Olivier, 2012). Along with the rapid clearance rate of DZP (Ramsay et al., 1979), this may explain the recurrence of seizures when DZP is used as an anticonvulsant treatment. Importantly, however, in a study where SE induced by exposure to paraoxon was controlled by administration of DZP at 1,3 , and 5 hours after exposure to prevent recurrence of seizures, long-term cognitive and behavioral, depressionlike deficits still developed (Deshpande et al., 2014b), suggesting that mechanisms other than seizure recurrence are involved in the inefficacy of DZP to protect against brain damage. Excessive increase in intracellular $\mathrm{Ca}^{2+}$ is largely responsible for seizure-induced neuronal degeneration and death (Holmes, 2002; Fujikawa, 2015), and prolonged elevations of intracellular $\mathrm{Ca}^{2+}$ have been found after acute organophosphate exposure despite treatment with DZP (Deshpande et al., 2014a). Apparently, enhancement of GABAergic inhibition by DZP does not adequately interfere with such $\mathrm{Ca}^{2+}$ elevations, which may in part explain the neuroprotective inefficacy of DZP. The insufficiency of targeting GABAergic inhibition to prevent brain damage may be particularly true in the young subjects, when $\mathrm{GABA}_{\mathrm{A}}$ receptor-mediated synaptic activity can be depolarizing (Ben-Ari et al., 2012; Khazipov et al., 2015), thus exacerbating rather than suppressing network hyperexcitability.

In contrast to DZP, LY293558, administered after about 50-55 minutes of sustained soman-induced SE, not only suppressed seizures, but it also reduced neuronal degeneration and prevented amygdala and hippocampal atrophy, reduction of background inhibitory activity in the BLA, as well as the development of behavioral deficits. The antiseizure and neuroprotective efficacy of LY293558 can be attributed to the suppression of both AMPA receptor- and GluK1containing kainate receptor activity. AMPA receptors, as primary mediators of glutamatergic transmission, are central to hyperexcitability, but they may also be directly involved in excitotoxicity by allowing $\mathrm{Ca}^{2+}$ influx (Kwak and Weiss, 2006; Yuan and Bellone, 2013). Their importance as targets for antiepileptic drugs has been emphasized previously (Rogawski, 2013; Serdyuk et al., 2014; Twele et al., 2015); however, the selectivity of LY293558 for the kainate receptors containing the GluK1 subunit is probably at least equally 
important as selective GluK1 receptor antagonists with minimal antagonistic activity for AMPA receptors can alone block pilocarpine-induced seizures (Smolders et al., 2002), as well soman-induced SE and neuropathology (Apland et al., 2014). The mechanisms underlying the role of GluK1 kainate receptors in hyperexcitability and neuronal damage (Jane et al., 2009) involve not only postsynaptic mediation of glutamatergic transmission in principal neurons (Gryder and Rogawski, 2003) but also suppression of GABA release (Braga et al., 2003), facilitation of glutamate release (Aroniadou-Anderjaska et al., 2012), and permeability to $\mathrm{Ca}^{2+}$ (Rogawski et al., 2003; Joseph et al., 2011).

Benefits of Combining CRM with LY293558. When LY293558 was coadministered with CRM, the latency to cessation of SE was significantly shorter than when LY293558 was injected alone, and full neuroprotection was achieved as suggested by the absence of degenerating neurons in all brain regions examined. CRM is an antimuscarinic compound (a selective M1 antagonist; Hudkins et al., 1993); as such, it can block nerve agent-induced SE, but only if administered soon after exposure, when seizure activity is still significantly dependent on muscarinic receptor hyperstimulation (Raveh et al., 2008). When CRM is administered alone at 1 hour after exposure of young adult rats to soman, it suppresses SE-albeit with a slow time course-and exerts neuroprotection, but only at the relatively high dose of $100 \mathrm{mg} / \mathrm{kg}$ (Figueiredo et al., 2011a). In addition to its antimuscarinic effects, CRM may suppress hyperexcitability by other mechanisms (Annels et al., 1991; Church and Fletcher, 1995; Thurgur and Church, 1998), but its NMDA receptor antagonistic properties (Apland and Braitman, 1990; Pontecorvo et al., 1991; Fletcher et al., 1995; Thurgur and Church, 1998; Figueiredo et al., 2011a) are likely to be primarily responsible for its neuroprotective efficacy (Raveh et al., 1999; Figueiredo et al., 2011a). In the P21 rats of the present study, a dose of $50 \mathrm{mg} / \mathrm{kg}$ did not suppress SE and did not prevent neuropathology when administered alone 1 hour after soman exposure. Extensive neurodegeneration was present in the CRM-treated group in all limbic structures studied, which probably explains the amygdala and hippocampal volume reduction. In addition, spontaneous inhibitory activity in the BLA was severely reduced in the CRM-treated group, and, consistent with the view that impaired inhibition in the BLA leads to anxiety (Shekhar et al., 2003; Truitt et al., 2009; Zhou et al., 2010), anxiety-like behavior was significantly increased (behavioral abnormalities after nerve agent exposure are reviewed in Aroniadou-Anderjaska et al., 2016). The synergistic neuroprotective effect seen when CRM was combined with LY293558 can probably be attributed in large part to the NMDA receptor antagonistic properties of CRM, but other mechanisms may also be involved to a lesser extent. The LY293558 + CRM combination treatment antagonizes AMPA, GluK1, and NMDA receptors, which, in contrast to the downregulation of $\mathrm{GABA}_{\mathrm{A}}$ receptors (Goodkin et al., 2005; Naylor et al., 2005; Deeb et al., 2012), are all upregulated by seizure activity (Ullal et al., 2005; Li et al., 2010; Naylor et al., 2013; Rajasekaran et al., 2013).

In neonatal rats (P7), use of the benzodiazepine midazolam as an anticonvulsant increased the injury associated with SE (Torolira et al., 2017). In the P21 rats of the present study, DZP did not worsen the brain damage induced by acute soman exposure, but it had little effect on neurodegeneration and did not prevent amygdalar and hippocampal volume reduction or increases in anxiety-like behavior. Therefore, in the event of mass exposure to nerve agents, if DZP is used to treat SE in children, lives may be saved, but the long-term morbidity can be expected to be high. In contrast, the combination of LY29358 + CRM not only can be expected to produce the highest survival rate but also to prevent long-term morbidity. CRM was approved by the FDA in 1973 as an over-the-counter antitussive for human use from the age of 2 years and older; FDA approval was withdrawn in 1984 because of the inefficacy of the drug as an antitussive, but not because of safety concerns. Clinical studies testing LY293558 against seizures of various causes are certainly feasible and can be performed to obtain a dose range of efficacy and safety in humans. A combination therapy of LY293558 with CRM, against nerve agent-induced SE, would allow reduction in the doses of both drugs, which would decrease the incidence of side effects and increase tolerability.

\section{Authorship Contributions}

Participated in research design: Braga, Aroniadou-Anderjaska, Apland.

Conducted experiments: Apland, Figueiredo, Pidoplichko.

Performed data analysis: Figueiredo, Pidoplichko, Rossetti, Apland, Braga, Aroniadou-Anderjaska.

Wrote or contributed to the writing of the manuscript: AroniadouAnderjaska, Apland, Braga, Figueiredo.

\section{References}

Anand A and Shekhar A (2003) Brain imaging studies in mood and anxiety disorders: special emphasis on the amygdala. Ann N Y Acad Sci 985:370-388.

Andersen SL (2003) Trajectories of brain development: point of vulnerability or window of opportunity? Neurosci Biobehav Rev 27:3-18.

Andreollo NA, Santos EF, Araújo MR, and Lopes LR (2012) Rat's age versus human's age: what is the relationship? Arq Bras Cir Dig 25:49-51.

Annels SJ, Ellis Y, and Davies JA (1991) Non-opioid antitussives inhibit endogenous glutamate release from rabbit hippocampal slices. Brain Res 564:341-343.

Apland JP, Aroniadou-Anderjaska V, Figueiredo TH, Green CE, Swezey R, Yang C, Qashu F, and Braga MF (2013) Efficacy of the GluK1/AMPA receptor antagonist LY293558 against seizures and neuropathology in a soman-exposure model without pretreatment and its pharmacokinetics after intramuscular administration. $J$ Pharmacol Exp Ther 344:133-140.

Apland JP, Aroniadou-Anderjaska V, Figueiredo TH, Rossetti F, Miller SL, and Braga MF (2014) The limitations of diazepam as a treatment for nerve agentinduced seizures and neuropathology in rats: comparison with UBP302. J Pharmacol Exp Ther 351:359-372.

Apland JP and Braitman DJ (1990) Effects of non-opioid antitussives on epileptiform activity and NMDA responses in hippocampal and olfactory cortex slices. Brain Res 529:277-285.

Apland JP, Figueiredo TH, Qashu F, Aroniadou-Anderjaska V, Souza AP, and Braga MF (2010) Higher susceptibility of the ventral versus the dorsal hippocampus and the posteroventral versus anterodorsal amygdala to soman-induced neuropathology. Neurotoxicology 31:485-492.

Aroniadou-Anderjaska V (2015) Anxiety and amygdalar hyperexcitability: the chicken or the egg? Ann Depress Anxiety 2:1038.

Aroniadou-Anderjaska V, Figueiredo TH, Apland JP, Prager EM, Pidoplichko VI, Miller SL, and Braga MF (2016) Long-term neuropathological and behavioral impairments after exposure to nerve agents. Ann N Y Acad Sci 1374:17-28.

Aroniadou-Anderjaska V, Pidoplichko VI, Figueiredo TH, Almeida-Suhett CP, Prager EM, and Braga MF (2012) Presynaptic facilitation of glutamate release in the basolateral amygdala: a mechanism for the anxiogenic and seizurogenic function of GluK1 receptors. Neuroscience 221:157-169.

Ben-Ari Y, Khalilov I, Kahle KT, and Cherubini E (2012) The GABA excitatory/inhibitory shift in brain maturation and neurological disorders. Neuroscientist 18:467-486.

Bleakman R, Schoepp DD, Ballyk B, Bufton H, Sharpe EF, Thomas K, Ornstein PL, and Kamboj RK (1996) Pharmacological discrimination of GluR5 and GluR6 kainate receptor subtypes by $(3 \mathrm{~S}, 4 \mathrm{aR}, 6 \mathrm{R}, 8 \mathrm{aR})-6$-[2-(1(2)H-tetrazole-5-yl)ethyl]decahyd roisdoquinoline-3 carboxylic-acid. Mol Pharmacol 49:581-585.

Braga MF, Aroniadou-Anderjaska V, Xie J, and Li H (2003) Bidirectional modulation of GABA release by presynaptic glutamate receptor 5 kainate receptors in the basolateral amygdala. J Neurosci 23:442-452.

Capacio BR, Byers CE, Merk KA, Smith JR, and McDonough JH (2004) Pharmacokinetic studies of intramuscular midazolam in guinea pigs challenged with soman. Drug Chem Toxicol 27:95-110.

Chapman S, Yaakov G, Egoz I, Rabinovitz I, Raveh L, Kadar T, Gilat E, and Grauer E (2015) Sarin-induced brain damage in rats is attenuated by delayed administration of midazolam. Neurotoxicology 49:132-138. 
Cherian A and Thomas SV (2009) Status epilepticus. Ann Indian Acad Neurol 12: 140-153.

Chung L and Moore SD (2009) Neuropeptides modulate compound postsynaptic potentials in basolateral amygdala. Neuroscience 164:1389-1397.

Church J and Fletcher EJ (1995) Blockade by sigma site ligands of high voltageactivated $\mathrm{Ca} 2+$ channels in rat and mouse cultured hippocampal pyramidal neurones. Br J Pharmacol 116:2801-2810.

de Araujo Furtado M, Lumley LA, Robison C, Tong LC, Lichtenstein S, and Yourick DL (2010) Spontaneous recurrent seizures after status epilepticus induced by soman in Sprague-Dawley rats. Epilepsia 51:1503-1510.

Deeb TZ, Maguire J, and Moss SJ (2012) Possible alterations in GABAA receptor signaling that underlie benzodiazepine-resistant seizures. Epilepsia 53 (Suppl 9): $79-88$

Deshpande LS, Carter DS, Phillips KF, Blair RE, and DeLorenzo RJ (2014a) Development of status epilepticus, sustained calcium elevations and neuronal injury in a rat survival model of lethal paraoxon intoxication. Neurotoxicology 44:17-26

Deshpande LS, Phillips K, Huang B, and DeLorenzo RJ (2014b) Chronic behavioral and cognitive deficits in a rat survival model of paraoxon toxicity. Neurotoxicology 44:352-357.

Dolgin E (2013) Syrian gas attack reinforces need for better anti-sarin drugs. Nat Med 19:1194-1195.

Etkin A and Wager TD (2007) Functional neuroimaging of anxiety: a meta-analysis of emotional processing in PTSD, social anxiety disorder, and specific phobia. Am J Psychiatry 164:1476-1488.

Figueiredo TH, Aroniadou-Anderjaska V, Qashu F, Apland JP, Pidoplichko V, Stevens D, Ferrara TM, and Braga MF (2011a) Neuroprotective efficacy of caramiphen against soman and mechanisms of its action. Br J Pharmacol 164:1495-1505.

Figueiredo TH, Qashu F, Apland JP, Aroniadou-Anderjaska V, Souza AP, and Braga MF (2011b) The GluK1 (GluR5) Kainate/alpha-amino-3-hydroxy-5-methyl-4isoxazolepropionic acid receptor antagonist LY293558 reduces soman-induced seizures and neuropathology. J Pharmacol Exp Ther 336:303-312.

Fletcher EJ, Church J, Abdel-Hamid K, and MacDonald JF (1995) Blockade by sigma site ligands of N-methyl-D-aspartate-evoked responses in rat and mouse cultured hippocampal pyramidal neurons. Br J Pharmacol 116:2791-2800.

Fujikawa DG (2015) The role of excitotoxic programmed necrosis in acute brain injury. Comput Struct Biotechnol J 13:212-221.

Gilat E, Kadar T, Levy A, Rabinovitz I, Cohen G, Kapon Y, Sahar R, and Brandeis R (2005) Anticonvulsant treatment of sarin-induced seizures with nasal midazolam: an electrographic, behavioral, and histological study in freely moving rats. Toxico Appl Pharmacol 209:74-85.

Goodkin HP, Liu X, and Holmes GL (2003) Diazepam terminates brief but not prolonged seizures in young, naïve rats. Epilepsia 44:1109-1112.

Goodkin HP, Yeh JL, and Kapur J (2005) Status epilepticus increases the intracellular accumulation of GABAA receptors. J Neurosci 25:5511-5520.

Gryder DS and Rogawski MA (2003) Selective antagonism of GluR5 kainate receptormediated synaptic currents by topiramate in rat basolateral amygdala neurons. $J$ Neurosci 23:7069-7074.

Gundersen HJ, Jensen EB, Kiêu K, and Nielsen J (1999) The efficiency of systematic sampling in stereology-reconsidered. J Microsc 193:199-211.

Holmes GL (2002) Seizure-induced neuronal injury: animal data. Neurology $\mathbf{5 9}$ (9 Suppl 5):S3-S6.

Hudkins RL, Stubbins JF, and DeHaven-Hudkins DL (1993) Caramiphen, iodocaramiphen and nitrocaramiphen are potent, competitive, muscarinic M1 receptorselective agents. Eur J Pharmacol 231:485-488.

Jane DE, Lodge D, and Collingridge GL (2009) Kainate receptors: pharmacology, function and therapeutic potential. Neuropharmacology 56:90-113.

Johnston MV (1994) Developmental aspects of NMDA receptor agonists and antagonists in the central nervous system. Psychopharmacol Bull 30:567-575.

Jones DM, Esmaeil N, Maren S, and Macdonald RL (2002) Characterization of pharmacoresistance to benzodiazepines in the rat Li-pilocarpine model of status epilepticus. Epilepsy Res 50:301-312.

Joseph DJ, Williams DJ, and MacDermott AB (2011) Modulation of neurite outgrowth by activation of calcium-permeable kainate receptors expressed by rat nociceptive-like dorsal root ganglion neurons. Dev Neurobiol 71:818-835.

Khazipov R, Valeeva G, and Khalilov I (2015) Depolarizing GABA and developmental epilepsies. CNS Neurosci Ther 21:83-91.

Kwak S and Weiss JH (2006) Calcium-permeable AMPA channels in neurodegenerative disease and ischemia. Curr Opin Neurobiol 16:281-287.

Lallement G, Dorandeu F, Filliat P, Carpentier P, Baille V, and Blanchet G (1998) Medical management of organophosphate-induced seizures. J Physiol Paris 92 369-373.

Langston JL, Wright LK, Connis N, and Lumley LA (2012) Characterizing the behavioral effects of nerve agent-induced seizure activity in rats: increased startle reactivity and perseverative behavior. Pharmacol Biochem Behav 100:382-391.

Li JM, Zeng YJ, Peng F, Li L, Yang TH, Hong Z, Lei D, Chen Z, and Zhou D (2010) Aberrant glutamate receptor 5 expression in temporal lobe epilepsy lesions. Brain Res 1311:166-174.

Li L, Du Y, Li N, Wu X, and Wu Y (2009) Top-down modulation of prepulse inhibition of the startle reflex in humans and rats. Neurosci Biobehav Rev 33:1157-1167.

Liu Y, Wong TP, Aarts M, Rooyakkers A, Liu L, Lai TW, Wu DC, Lu J, Tymianski M, Craig AM, et al. (2007) NMDA receptor subunits have differential roles in mediating excitotoxic neuronal death both in vitro and in vivo. $J$ Neurosci 27: $2846-2857$.

McDonough JH Jr, McMonagle JD, and Shih TM (2010) Time-dependent reduction in the anticonvulsant effectiveness of diazepam against soman-induced seizures in guinea pigs. Drug Chem Toxicol 33:279-283.

McDonough JH Jr and Shih TM (1997) Neuropharmacological mechanisms of nerve agent-induced seizure and neuropathology. Neurosci Biobehav Rev 21:559-579.

McDonough JH, Van Shura KE, LaMont JC, McMonagle JD, and Shih TM (2009)

Comparison of the intramuscular, intranasal or sublingual routes of midazolam administration for the control of soman-induced seizures. Basic Clin Pharmacol Toxicol 104:27-34.

Miller SL, Aroniadou-Anderjaska V, Figueiredo TH, Prager EM, Almeida-Suhett CP, Apland JP, and Braga MF (2015) A rat model of nerve agent exposure applicable to the pediatric population: the anticonvulsant efficacies of atropine and GluK1 antagonists. Toxicol Appl Pharmacol 284:204-216.

Muller JF, Mascagni F, and McDonald AJ (2005) Coupled networks of parvalbuminimmunoreactive interneurons in the rat basolateral amygdala. $J$ Neurosci 25 : $7366-7376$

Murata K, Araki S, Yokoyama K, Okumura T, Ishimatsu S, Takasu N, and White RF (1997) Asymptomatic sequelae to acute sarin poisoning in the central and autonomic nervous system 6 months after the Tokyo subway attack. $J$ Neurol 244: 601-606.

Naylor DE, Liu H, Niquet J, and Wasterlain CG (2013) Rapid surface accumulation of NMDA receptors increases glutamatergic excitation during status epilepticus. Neurobiol Dis 54:225-238.

Naylor DE, Liu H, and Wasterlain CG (2005) Trafficking of GABA(A) receptors, loss of inhibition, and a mechanism for pharmacoresistance in status epilepticus. $J$ Neurosci 25:7724-7733.

Niquet J, Baldwin R, Suchomelova L, Lumley L, Naylor D, Eavey R, and Wasterlain CG (2016) Benzodiazepine-refractory status epilepticus: pathophysiology and principles of treatment. Ann N Y Acad Sci 1378:166-173.

Ohshiro H, Kubota S, and Murakoshi T (2011) Dopaminergic modulation of oscillatory network inhibition in the rat basolateral amygdala depends on initial activity state. Neuropharmacology 61:857-866.

Ohtani T, Iwanami A, Kasai K, Yamasue H, Kato T, Sasaki T, and Kato N (2004) Post-traumatic stress disorder symptoms in victims of Tokyo subway attack: a 5-year follow-up study. Psychiatry Clin Neurosci 58:624-629.

Pan BX, Dong Y, Ito W, Yanagawa Y, Shigemoto R, and Morozov A (2009) Selective gating of glutamatergic inputs to excitatory neurons of amygdala by presynaptic GABAb receptor. Neuron 61:917-929.

Park K, Lee S, Kang SJ, Choi S, and Shin KS (2007) Hyperpolarization-activated currents control the excitability of principal neurons in the basolateral amygdala. Biochem Biophys Res Commun 361:718-724.

Paxinos G and Watson C (2005) The Rat Brain in Stereotaxic Coordinates, 4th ed. Elsevier, New York.

Pereira EF, Aracava Y, DeTolla LJ Jr, Beecham EJ, Basinger GW Jr, Wakayama EJ, and Albuquerque EX (2014) Animal models that best reproduce the clinical manifestations of human intoxication with organophosphorus compounds. J Pharmacol Exp Ther 350:313-321.

Phelps EA and LeDoux JE (2005) Contributions of the amygdala to emotion processing: from animal models to human behavior. Neuron 48:175-187.

Pidoplichko VI, Aroniadou-Anderjaska V, Prager EM, Figueiredo TH, AlmeidaSuhett CP, Miller SL, and Braga MF (2014) ASIC1a activation enhances inhibition in the basolateral amygdala and reduces anxiety. $J$ Neurosci 34:3130-3141.

Pontecorvo MJ, Karbon EW, Goode S, Clissold DB, Borosky SA, Patch RJ, and Ferkany JW (1991) Possible cerebroprotective and in vivo NMDA antagonist activities of sigma agents. Brain Res Bull 26:461-465.

Popescu AT and Paré D (2011) Synaptic interactions underlying synchronized inhibition in the basal amygdala: evidence for existence of two types of projection cells. J Neurophysiol 105:687-696.

Portera-Cailliau C, Price DL, and Martin LJ (1997) Non-NMDA and NMDA receptormediated excitotoxic neuronal deaths in adult brain are morphologically distinct further evidence for an apoptosis-necrosis continuum. J Comp Neurol 378:88-104.

Prager EM, Aroniadou-Anderjaska V, Almeida-Suhett CP, Figueiredo TH, Apland JP, and Braga MF (2013) Acetylcholinesterase inhibition in the basolateral amygdala plays a key role in the induction of status epilepticus after soman exposure. Neurotoxicology 38:84-90

Prager EM, Figueiredo TH, Long RP II, Aroniadou-Anderjaska V, Apland JP and Braga MF (2015) LY293558 prevents soman-induced pathophysiological alterations in the basolateral amygdala and the development of anxiety. Neuropharmacology 89:11-18.

Prager EM, Pidoplichko VI, Aroniadou-Anderjaska V, Apland JP, and Braga MF (2014) Pathophysiological mechanisms underlying increased anxiety after soman exposure: reduced GABAergic inhibition in the basolateral amygdala. Neurotoxicology 44:335-343.

Pressler R and Auvin S (2013) Comparison of brain maturation among species: an example in translational research suggesting the possible use of bumetanide in newborn. Front Neurol 4:36.

Prut L and Belzung C (2003) The open field as a paradigm to measure the effects of drugs on anxiety-like behaviors: a review. Eur J Pharmacol 463:3-33.

Qashu F, Figueiredo TH, Aroniadou-Anderjaska V, Apland JP, and Braga MF (2010) Diazepam administration after prolonged status epilepticus reduces neurodegeneration in the amygdala but not in the hippocampus during epileptogenesis. Amino Acids 38:189-197.

Racine RJ (1972) Modification of seizure activity by electrical stimulation. II. Motor seizure. Electroencephalogr Clin Neurophysiol 32:281-294.

Rainnie DG (1999) Serotonergic modulation of neurotransmission in the rat basolateral amygdala. J Neurophysiol 82:69-85.

Rajasekaran K, Joshi S, Kozhemyakin M, Todorovic MS, Kowalski S, Balint C, and Kapur J (2013) Receptor trafficking hypothesis revisited: plasticity of AMPA receptors during established status epilepticus. Epilepsia 54 (Suppl 6):14-16.

RamaRao G, Afley P, Acharya J, and Bhattacharya BK (2014) Efficacy of antidotes (midazolam, atropine and HI-6) on nerve agent induced molecular and neuropathological changes. BMC Neurosci 15:47.

Ramsay RE, Hammond EJ, Perchalski RJ, and Wilder BJ (1979) Brain uptake of phenytoin, phenobarbital, and diazepam. Arch Neurol 36:535-539.

Raveh L, Brandeis R, Gilat E, Cohen G, Alkalay D, Rabinovitz I, Sonego H, and Weissman BA (2003) Anticholinergic and antiglutamatergic agents protect 
against soman-induced brain damage and cognitive dysfunction. Toxicol Sci $\mathbf{7 5}$ : $108-116$

Raveh L, Chapman S, Cohen G, Alkalay D, Gilat E, Rabinovitz I, and Weissman BA (1999) The involvement of the NMDA receptor complex in the protective effect of anticholinergic drugs against soman poisoning. Neurotoxicology 20:551-559.

Raveh L, Rabinovitz I, Gilat E, Egoz I, Kapon J, Stavitsky Z, Weissman BA, and Brandeis R (2008) Efficacy of antidotal treatment against sarin poisoning: the superiority of benactyzine and caramiphen. Toxicol Appl Pharmacol 227:155-162.

Reddy SD and Reddy DS (2015) Midazolam as an anticonvulsant antidote for organophosphate intoxication-a pharmacotherapeutic appraisal. Epilepsia 56: 813-821.

Rogawski MA (2013) AMPA receptors as a molecular target in epilepsy therapy. Acto Neurol Scand Suppl 197:9-18.

Rogawski MA, Gryder D, Castaneda D, Yonekawa W, Banks MK, and Lia H (2003) GluR5 kainate receptors, seizures, and the amygdala. Ann N Y Acad Sci 985:150-162.

Sah P, Faber ES, Lopez De Armentia M, and Power J (2003) The amygdaloid complex: anatomy and physiology. Physiol Rev 83:803-834.

Sajdyk TJ and Shekhar A (1997) Excitatory amino acid receptor antagonists block the cardiovascular and anxiety responses elicited by gamma-aminobutyric acidA receptor blockade in the basolateral amygdala of rats. J Pharmacol Exp Ther 283:969-977.

Sekijima Y, Morita H, and Yanagisawa N (1997) Follow-up of sarin poisoning in Matsumoto. Ann Intern Med 127:1042.

Sengupta P (2013) The laboratory rat: relating its age with human's. Int J Prev Med 4:624-630.

Serdyuk SE, Gmiro VE, and Veselkina OS (2014) Combined blockade of NMDA and AMPA receptors prevents acute kainate seizures and chronic kainate lethality in rats. Bull Exp Biol Med 157:15-17.

Shekhar A, Sajdyk TJ, Gehlert DR, and Rainnie DG (2003) The amygdala, panic disorder, and cardiovascular responses. Ann N Y Acad Sci 985:308-325.

Shih TM, Duniho SM, and McDonough JH Jr (2003) Control of nerve agent-induced seizures is critical for neuroprotection and survival. Toxicol Appl Pharmacol 188:69-80.

Shih TM and McDonough JH Jr (1999) Organophosphorus nerve agents-induced seizures and efficacy of atropine sulfate as anticonvulsant treatment. Pharmacol Biochem Behav 64:147-153.

Sirin GS, Zhou Y, Lior-Hoffmann L, Wang S, and Zhang Y (2012) Aging mechanism of soman inhibited acetylcholinesterase. J Phys Chem B 116:12199-12207.

Skovira JW, McDonough JH Jr, and Shih TM (2010) Protection against sarin-induced seizures in rats by direct brain microinjection of scopolamine, midazolam or MK-801. J Mol Neurosci 40:56-62.

Smolders I, Bortolotto ZA, Clarke VR, Warre R, Khan GM, O’Neill MJ, Ornstein PL, Bleakman D, Ogden A, Weiss B, et al. (2002) Antagonists of GLU(K5)-containing kainate receptors prevent pilocarpine-induced limbic seizures. Nat Neurosci 5 796-804.

Stein MB and Stein DJ (2008) Social anxiety disorder. Lancet 371:1115-1125.

Thurgur C and Church J (1998) The anticonvulsant actions of sigma receptor ligands in the $\mathrm{Mg} 2+$-free model of epileptiform activity in rat hippocampal slices. $\mathrm{Br} J$ Pharmacol 124:917-929.

Todorovic MS, Cowan ML, Balint CA, Sun C, and Kapur J (2012) Characterization of status epilepticus induced by two organophosphates in rats. Epilepsy Res 101: 268-276
Torolira D, Suchomelova L, Wasterlain CG, and Niquet J (2017) Phenobarbital and midazolam increase neonatal seizure-associated neuronal injury. Ann Neurol 82: $115-120$.

Trinka E and Kälviäinen R (2017) 25 years of advances in the definition, classification and treatment of status epilepticus. Seizure 44:65-73.

Truitt WA, Johnson PL, Dietrich AD, Fitz SD, and Shekhar A (2009) Anxiety-like behavior is modulated by a discrete subpopulation of interneurons in the basolateral amygdala. Neuroscience 160:284-294.

Twele F, Bankstahl M, Klein S, Römermann K, and Löscher W (2015) The AMPA receptor antagonist NBQX exerts anti-seizure but not antiepileptogenic effects in the intrahippocampal kainate mouse model of mesial temporal lobe epilepsy. Neuropharmacology 95:234-242.

Ullal G, Fahnestock M, and Racine R (2005) Time-dependent effect of kainateinduced seizures on glutamate receptor GluR5, GluR6, and GluR7 mRNA and protein expression in rat hippocampus. Epilepsia 46:616-623.

Uusi-Oukari M and Korpi ER (2010) Regulation of GABA(A) receptor subunit expression by pharmacological agents. Pharmacol Rev 62:97-135.

Vazdarjanova A, Cahill L, and McGaugh JL (2001) Disrupting basolateral amygdala function impairs unconditioned freezing and avoidance in rats. Eur J Neurosci 14: $709-718$.

Vinkers CH and Olivier B (2012) Mechanisms underlying tolerance after long-term benzodiazepine use: a future for subtype-selective GABA(A) receptor modulators? Adv Pharmacol Sci 2012:416864.

Walton NY and Treiman DM (1991) Motor and electroencephalographic response of refractory experimental status epilepticus in rats to treatment with MK-801, diazepam, or MK-801 plus diazepam. Brain Res 553:97-104.

Wang DV, Wang F, Liu J, Zhang L, Wang Z, and Lin L (2011) Neurons in the amygdala with response-selectivity for anxiety in two ethologically based tests. PLoS One 6:e18739.

Wasterlain CG, Naylor DE, Liu H, Niquet J, and Baldwin R (2013) "https://www.ncbi. nlm.nih.gov/pubmed/24001081" Trafficking of NMDA receptors during status epilepticus: therapeutic implications. Epilepsia 6:78-80.

Yanagisawa N, Morita H, and Nakajima T (2006) Sarin experiences in Japan: acute toxicity and long-term effects. $J$ Neurol Sci 249:76-85.

Yokoyama K (2007) Our recent experiences with sarin poisoning cases in Japan and pesticide users with references to some selected chemicals. Neurotoxicology 28 364-373.

Yuan T and Bellone C (2013) Glutamatergic receptors at developing synapses: the role of GluN3A-containing NMDA receptors and GluA2-lacking AMPA receptors. Eur J Pharmacol 719:107-111.

Zhou R, Wang S, and Zhu X (2010) Prenatal ethanol exposure attenuates GABAergic inhibition in basolateral amygdala leading to neuronal hyperexcitability and anxiety-like behavior of adult rat offspring. Neuroscience 170:749-757.

Address correspondence to: Dr. Maria F. M. Braga, Department of Anatomy, Physiology, and Genetics, Uniformed Services University of the Health Sciences, 4301 Jones Bridge Road, Bethesda, MD 20814. E-mail: maria. braga@usuhs.edu 